\title{
The Synthetic Potential of Fungal Feruloyl Esterases: A Correlation with Current Classification Systems and Predicted Structural Properties
}

\author{
Io Antonopoulou ${ }^{1}$ (D), Adiphol Dilokpimol ${ }^{2}$ (D), Laura Iancu ${ }^{3}$, Miia R. Mäkelä ${ }^{4}$ (D), \\ Simona Varriale ${ }^{5}$, Gabriella Cerullo ${ }^{5}$, Silvia Hüttner ${ }^{6}{ }^{(1)}$, Stefan Uthoff ${ }^{7}$, Peter Jütten ${ }^{8}$, \\ Alexander Piechot ${ }^{8}$, Alexander Steinbüchel ${ }^{7,9}$, Lisbeth Olsson ${ }^{6}$, Vincenza Faraco ${ }^{5}$, \\ Kristiina S. Hildén ${ }^{4}$, Ronald P. de Vries ${ }^{2}$ (D), Ulrika Rova ${ }^{1}$ (D) and Paul Christakopoulos ${ }^{1, *}$ \\ 1 Biochemical Process Engineering, Division of Chemical Engineering, Department of Civil, \\ Environmental and Natural Resources Engineering, Luleå University of Technology, \\ SE-97187 Luleå, Sweden; io.antonopoulou@ltu.se (I.A.); ulrika.rova@ltu.se (U.R.) \\ 2 Fungal Physiology, Westerdijk Fungal Biodiversity Institute \& Fungal Molecular Physiology, \\ Utrecht University, Uppsalalaan 8, 3584 CT Utrecht, The Netherlands; \\ a.dilokpimol@westerdijkinstitute.nl (A.D.); r.devries@westerdijkinstitute.nl (R.P.d.V.) \\ 3 Dupont Industrial Biosciences, Nieuwe Kanaal 7-S, 6709 PA Wageningen, The Netherlands; \\ laura.iancu@dupont.com \\ 4 Department of Microbiology, University of Helsinki, Viikinkaari 9, 00014-FIN Helsinki, Finland; \\ miia.r.makela@helsinki.fi (M.R.M.); kristiina.s.hilden@helsinki.fi (K.S.H.) \\ 5 Department of Chemical Sciences, University of Naples "Federico II", Complesso Universitario Monte S. \\ Angelo Via Cintia, 4 IT-80126 Naples, Italy; simona.varriale@unina.it (S.V.); gabriella.cerullo@unina.it (G.C.); \\ vfaraco@unina.it (V.F.) \\ 6 Department of Biology and Biological Engineering, Division of Industrial Biotechnology, \\ Chalmers University of Technology, SE-41296 Gothenburg, Sweden; huttner@chalmers.se (S.H.); \\ lisbeth.olsson@chalmers.se (L.O.) \\ 7 Institut für Molekulare Mikrobiologie und Biotechnologie, Westfälische Wilhelms-Universität Münster, \\ Corrensstraße 3, 48149 Münster, Germany; uthoffs@uni-muenster.de (S.U.); steinbu@uni-muenster.de (A.S.) \\ 8 Taros Chemicals GmbH \& Co KG, Emil-Figge-Str. 76a, 44227 Dortmund, Germany; pjuetten@taros.de (P.J.); \\ apiechot@taros.de (A.P.) \\ 9 Environmental Sciences Department, King Abdulaziz University, Jeddah 21589, Saudi Arabia \\ * Correspondence: paul.christakopoulos@ltu.se; Tel.: +46-(0)920-492510
}

Received: 21 May 2018; Accepted: 1 June 2018; Published: 7 June 2018

\begin{abstract}
Twenty-eight fungal feruloyl esterases (FAEs) were evaluated for their synthetic abilities in a ternary system of $n$-hexane: $t$-butanol: $100 \mathrm{mM}$ MOPS-NaOH pH 6.0 forming detergentless microemulsions. Five main derivatives were synthesized, namely prenyl ferulate, prenyl caffeate, butyl ferulate, glyceryl ferulate, and L-arabinose ferulate, offering, in general, higher yields when more hydrophilic alcohol substitutions were used. Acetyl xylan esterase-related FAEs belonging to phylogenetic subfamilies (SF) 5 and 6 showed increased synthetic yields among tested enzymes. In particular, it was shown that FAEs belonging to SF6 generally transesterified aliphatic alcohols more efficiently while SF5 members preferred bulkier L-arabinose. Predicted surface properties and structural characteristics were correlated with the synthetic potential of selected tannase-related, acetyl-xylan-related, and lipase-related FAEs (SF1-2, -6, -7 members) based on homology modeling and small molecular docking simulations.
\end{abstract}

Keywords: transesterification; feruloyl esterase; antioxidants; phylogenetic classification; prenyl ferulate; prenyl caffeate; glyceryl ferulate; butyl ferulate; L-arabinose ferulate; sugar esters 


\section{Introduction}

Feruloyl esterases (EC 3.1.1.73, FAEs) are a subclass of carbohydrate esterases generally known for their role as accessory enzymes during the enzymatic hydrolysis of lignocellulosic biomass, being able to break down the ester bond between hydroxycinnamic acids, such as ferulic acid (FA), sinapic acid (SA), caffeic acid (CA), and $p$-coumaric acid $(p C A)$ and sugars in plant cell walls. During the last 16 years, FAEs have gained increased attention as tools for the synthesis of novel hydroxycinnamates with enhanced anti-oxidant activity and tailor-made lipophilicity with potential applications in the food, pharmaceutical, and cosmetics industries [1-12].

Contrary to lipases, which perform best in pure solvents, the vast majority of synthetic reactions based on FAEs have been performed in ternary solvent systems forming detergentless microemulsions, since FAEs often inactivate during incubation in pure solvents with very low or no water content $[13,14]$. In detergentless microemulsions, the enzyme is enclosed inside aqueous microdroplets stabilized by a polar alcohol in a hydrocarbon solvent which offers enzyme stability and protection from inactivation [15]. At the same time, they are an attractive medium for screening the synthetic potential of enzymes as they exclude possible interference (activation) or adverse solvent effects (inactivation) for the stability and activity.

FAEs are very diverse enzymes, with low unifying sequence identity and few physicochemical characteristics linking them [16-18]. The initial classification of FAEs (type A-D) was based on their hydrolytic activities towards model substrates (methyl ferulate, MFA; methyl sinapate, MSA; methyl caffeate, MCA, and methyl $p$-coumarate; MpCA) and was later supported by amino acid similarity and phylogenetic analysis [19]. Shortly, Type A FAEs prefer methoxy substitutions at the C 3 and/or C5 of hydroxycinnamate, as found in MFA and MSA and are active towards M $p$ CA and diferulates, but not MCA. Type B FAEs prefer hydroxy substitutions, as found in MpCA and MCA. Hydrolytic rates of type B FAEs are significantly reduced when a methoxy group is present and they are not active against MSA or diferulates. Type $C$ and D FAEs have broader substrate specificities with activities towards all model substrates, but only type $\mathrm{D}$ can release diferulates from plant cells walls.

As molecular techniques and genome sequencing have developed rapidly, the ABCD classification system no longer adequately represented the predominance of putative fungal and bacterial FAEs and their evolutionary relationships. Based on phylogenetic analysis of available fungal genomes, a refined classification was introduced proposing a classification system of seven subfamilies (SF1-7) [20]. Recently, this system was expanded into thirteen subfamilies (SF1-13) [18]. According to the updated classification, FAEs evolved from diverse classes of enzymes; SF1-4 and SF9-11 are related to tannases, SF5-6 to acetyl xylan esterases, SF7 to lipases and SF12-13 to both lipases and choline esterases. SF1-3 and SF5-7 remained classified to the same subfamilies as previously. In comparison with the ABCD system, SF6 and 7 contain only type B and A FAEs, respectively, SF1 contains both B and C FAEs and SF5 a mix of type A and D. The new subfamilies SF8 and SF12, which are distantly related to SF7, contain type A FAEs. SF13 distantly related to SF6, includes type B activity.

So far, FAE research has mainly been focused on the study of their hydrolytic activity, as well as their classification, and less attention has been paid to the systematic assessment of enzyme characteristics that could identify promising candidates with high synthetic potential. FAEs are considered ideal candidates for the synthesis of hydroxycinnamate derivatives due to their high specificity for these compounds which is superior to other esterases, such as lipases. However, it is often challenging to find the optimal biocatalyst for the development of a biosynthetic process. In 2014, the EU collaborative project "OPTIBIOCAT" was granted by the 7th Framework Programme (FP7) aiming to use esterases, such as FAEs, as biocatalysts for the synthesis of potential antioxidants for cosmetic products.

In the present work, we evaluated the ability of 28 fungal FAEs to transesterify acceptors of different lipophilicity in detergentless microemulsions. Five main targeted compounds were synthesized: Prenyl ferulate (PFA), prenyl caffeate (PCA), butyl ferulate (BFA), glyceryl ferulate (GFA), and L-arabinose ferulate (AFA) by transesterification of an activated donor (vinyl ferulate, VFA or 
vinyl caffeate, VCA) with the respective acceptor (prenol, 1-butanol, glycerol, or L-arabinose) (Figure 1). The results provided an insight into the desired characteristics of a biocatalyst for the synthesis of antioxidant products. Homology modeling of selected FAEs and small molecule docking (SMD) simulations were performed to point towards residues and structural or surface properties that could influence transesterification selectivity.

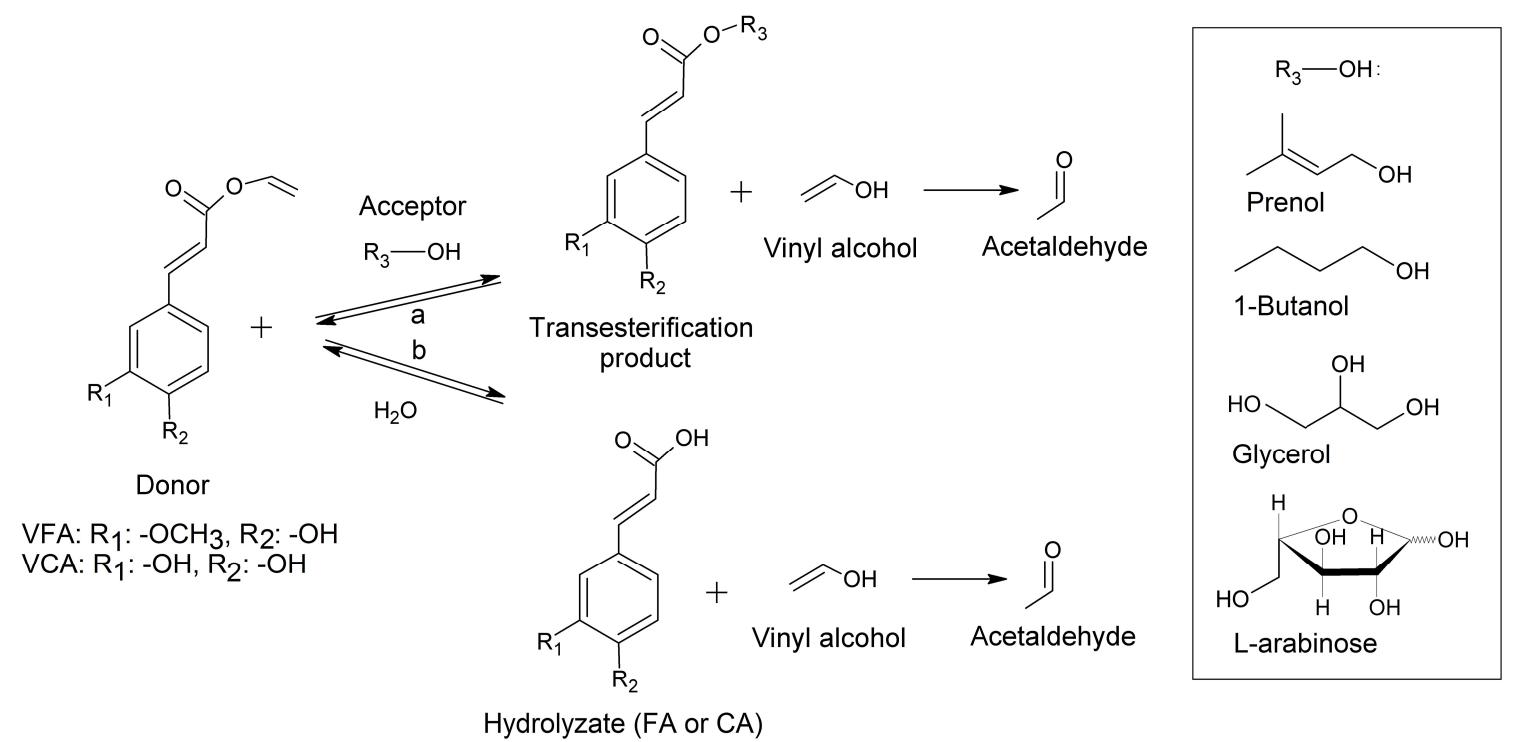

Figure 1. (a) Transesterification of a vinyl activated donor with acceptors of different lipophilicity (prenol, 1-butanol, glycerol, or L-arabinose); (b) Hydrolysis of donor observed as side-reaction during transesterification. Under normal conditions vinyl alcohol tautomerizes to acetaldehyde.

\section{Results and Discussion}

\subsection{Synthesis of Aliphatic Esters}

Twenty-eight FAEs from 13 different fungal species (Table 1) were screened for their potential to synthesize bioactive compounds of different lipophilicity. Screening of FAEs using different alcohol acceptors showed that higher transesterification rates, yields, and selectivities were observed for more hydrophilic/polar alcohols and, in decreasing order of preference, of glycerol $(\log \mathrm{P}-1.85)>$ 1-butanol $(\log \mathrm{P} 0.88)>$ prenol $(\log \mathrm{P} 1.09)$ for both tested conditions $(200 \mathrm{mM}$ or $800 \mathrm{mM})$. The only exception was Fae68 from Talaromyces wortmannii (SF1) for which the opposite trend was observed. Overall, the transesterification trend/pattern among evaluated FAEs was quite similar between different alcohol acceptors at given conditions (correlation coefficient $>0.7694$ ). Screening of FAEs at low (200 mM; Figure S1) and high acceptor concentration ( $800 \mathrm{mM}$; Figure 2) confirmed that the acceptor concentration is a crucial parameter in enzymatic transesterification. A four-fold increase in acceptor concentration (from 200 to $800 \mathrm{mM}$ ) resulted in approximately a two-fold increase in the transesterification yield and rate. Selectivity was impacted by acceptor concentration to a higher degree when a lipophilic/apolar acceptor was used: prenol (three-fold increase) > 1-butanol (2.5-fold increase) $>$ glycerol (two-fold increase). 


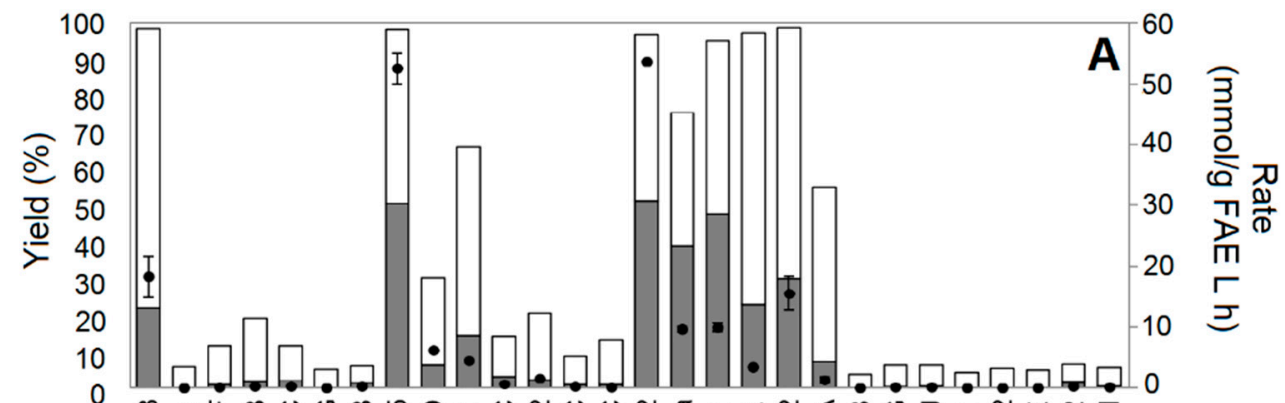

:

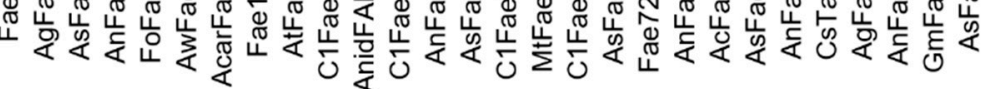

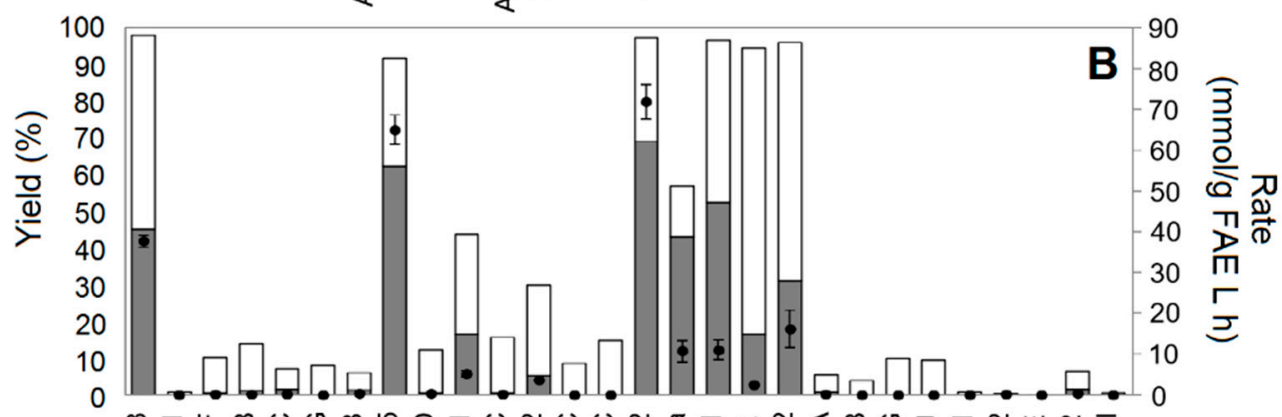

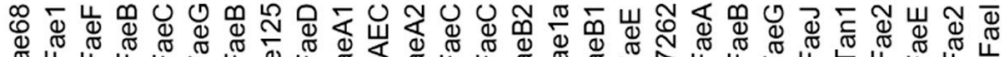

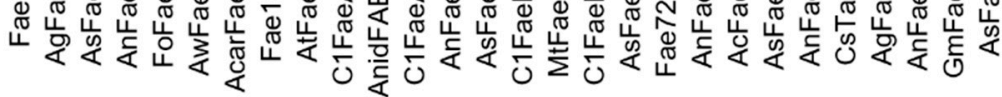
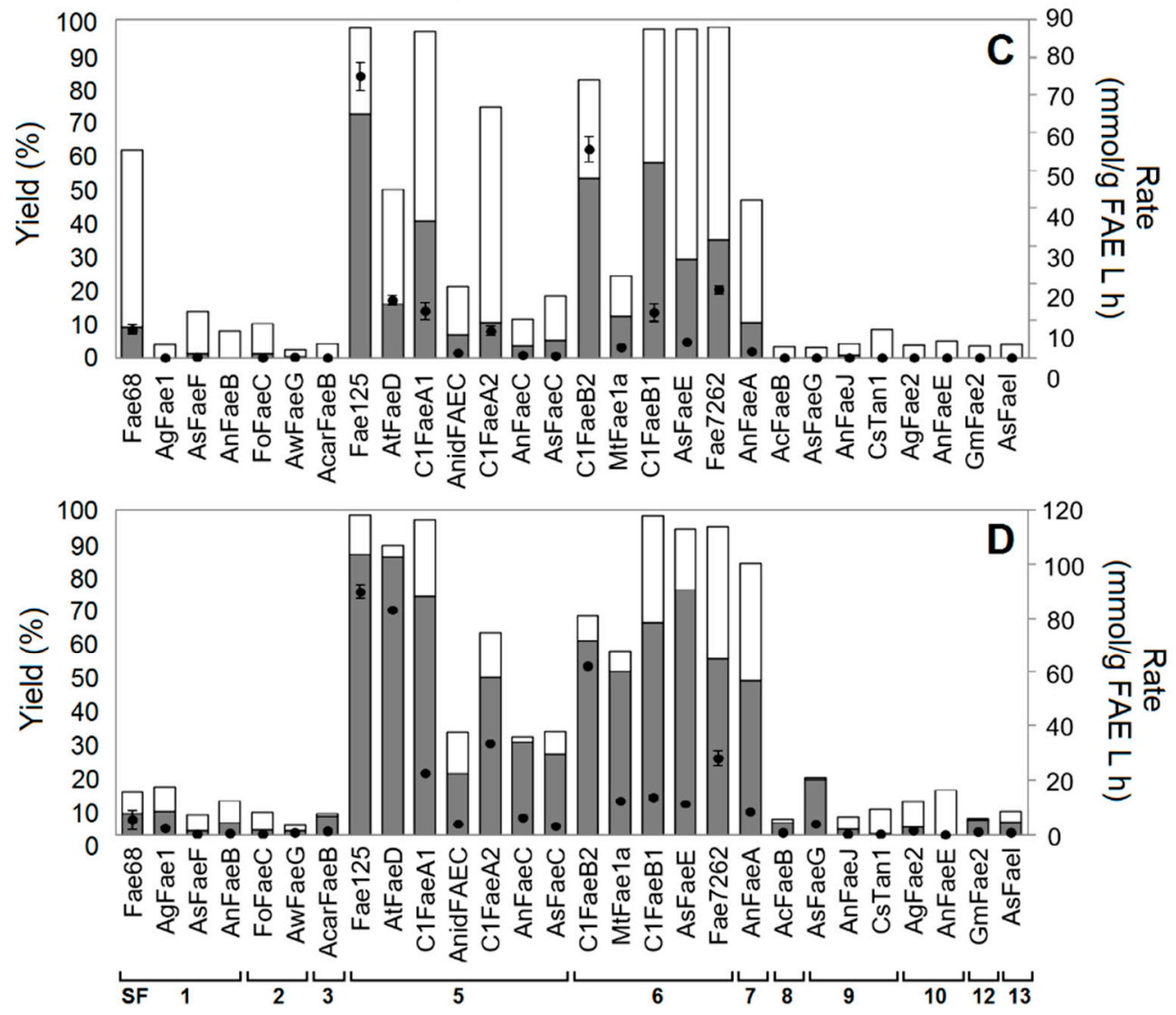

Figure 2. Synthesis of (A) PFA, (B) PCA, (C) BFA, and (D) GFA. Reaction conditions: 50 mM donor (VFA or VCA), $800 \mathrm{mM}$ acceptor, $0.2 \mathrm{mg}$ protein $\mathrm{mL}^{-1}$, 53.4:43.4:3.2 $v / v / v$-hexane: $t$-butanol: buffer, $45^{\circ} \mathrm{C}$, no agitation, $24 \mathrm{~h}$ of incubation. Grey column: transesterification yield; white column: hydrolysis yield; black circle: specific rate of transesterification. The error bars represent the standard deviation between two duplicates. 
Table 1. Characteristics of feruloyl esterases.

\begin{tabular}{|c|c|c|c|c|c|c|c|c|c|c|}
\hline $\begin{array}{l}\text { Enzyme } \\
\text { Sample }\end{array}$ & Origin & Expression & $\begin{array}{l}\text { Calculated/ } \\
\text { Observed } \\
\text { MW (kDa) }\end{array}$ & $\begin{array}{l}\text { Calculated } \\
\text { pI }\end{array}$ & $\begin{array}{c}\mathrm{N}- \\
\text { Glycosylation }\end{array}$ & $\begin{array}{c}O- \\
\text { Glycosylation }\end{array}$ & $\begin{array}{l}\text { FAE Content }(\% \mathrm{~g} \\
\text { FAE } \mathrm{g}^{-1} \text { Protein) }\end{array}$ & $\begin{array}{l}\text { Nucleophilic } \\
\text { Elbow }\end{array}$ & $\mathrm{SF}^{\mathrm{a}}$ & Accession Number \\
\hline \multicolumn{11}{|c|}{ Fungal FAEs } \\
\hline Fae68 & Talaromyces wortmannii & $\begin{array}{l}\text { Myceliophthora } \\
\text { thermophila C1 }\end{array}$ & $58.7 / 58.8$ & 4.96 & 10 & 11 & $10-15$ & GCSTG & 1 & MF362596 \\
\hline AgFae1 & Aspergillus glaucus & Pichia pastoris & $55.8 / 75$ & 5.49 & 7 & 1 & 31.3 & GCSTG & 1 & OJJ86166 \\
\hline AsFaeF & Aspergillus sydowii & Pichia pastoris & $55.4 / 75$ & 4.89 & 6 & 1 & 67.5 & GCSTG & 1 & jgi | Aspsy1 | 293049 \\
\hline AnFaeB & Aspergillus niger & Pichia pastoris & $55.6 / 74$ & 4.99 & 12 & 3 & 60.3 & GCSTG & 1 & Q8WZI8 \\
\hline FoFaeC & Fusarium oxysporum & Pichia pastoris & $62.0 / 62$ & 6.39 & 6 & 3 & 86.7 & GCSTG & 2 & jgi | Fusox1 | 5438 \\
\hline AwFaeG & Aspergillus wentii & Pichia pastoris & $58.2 / 58$ & 5.03 & 7 & 11 & 17.2 & GCSTG & 2 & jgi | Aspwe1 | 156253 \\
\hline AcarFaeB & Aspergillus carbonarius & Pichia pastoris & $56.0 / 58$ & 5.02 & 5 & 2 & $\mathrm{n} / \mathrm{q}$ & GCSFG & 3 & jgi | Aspca3 | 176503 \\
\hline Fae125 b & Talaromyces wortmannii & $\begin{array}{l}\text { Myceliophthora } \\
\text { thermophila C1 }\end{array}$ & $33.9 / 40$ & 5.64 & 0 & 22 & 10 & GWSYG & 5 & MF362595 \\
\hline AtFaeD & Aspergillus terreus & Pichia pastoris & $26.5 / 43$ & 4.22 & 0 & 1 & 10.7 & GWSWG & 5 & XP_001215822 \\
\hline C1FaeA1 & Myceliophthora thermophila C1 & $\begin{array}{l}\text { Myceliophthora } \\
\text { thermophila C1 }\end{array}$ & $27.2 / 29$ & 6.15 & 0 & 2 & 33.7 & GWSYG & 5 & JF826027 \\
\hline AnidFAEC & Aspergillus nidulans & Pichia pastoris & $25.8 / 30$ & 4.47 & 0 & 2 & 52.9 & GFSWG & 5 & EAA62427 \\
\hline C1FaeA2 & Myceliophthora thermophila C1 & $\begin{array}{l}\text { Myceliophthora } \\
\text { thermophila C1 }\end{array}$ & $29.1 / 36$ & 5.05 & 1 & 8 & 15.0 & GFSYG & 5 & JF826028 \\
\hline AnFaeC & Aspergillus niger & Pichia pastoris & $28.2 / 30$ & 4.44 & 1 & 1 & 47.3 & GFSWG & 5 & An12g02550 \\
\hline AsFaeC & Aspergillus sydowii & Pichia pastoris & $25.9 / 30$ & 4.44 & 0 & 0 & 83.2 & GFSWG & 5 & jgi | Aspsy1 | 154482 \\
\hline C1FaeB2 ${ }^{\mathrm{c}}$ & Myceliophthora thermophila C1 & $\begin{array}{l}\text { Myceliophthora } \\
\text { thermophila C1 }\end{array}$ & $28.4 / 33$ & 4.57 & 2 & 1 & 10.0 & GFSSG & 6 & JF826029 \\
\hline MtFae1a ${ }^{c}$ & Myceliophthora thermophila ATCC 42464 & Pichia pastoris & $28.4 / 39$ & 4.57 & 2 & 1 & 42.2 & GFSSG & 6 & AEO62008 \\
\hline C1FaeB1 & Myceliophthora thermophila $\mathrm{C} 1$ & $\begin{array}{l}\text { Myceliophthora } \\
\text { thermophila C1 }\end{array}$ & $28.3 / 29$ & 5.74 & 1 & 2 & 50.0 & GGSSG & 6 & API68922 \\
\hline AsFaeE & Aspergillus sydowii & Pichia pastoris & $29.5 / 32$ & 4.24 & 2 & 1 & 70.0 & GSSSG & 6 & jgi | Aspsy1 | 1158585 \\
\hline Fae7262 b & Talaromyces wortmannii & $\begin{array}{l}\text { Myceliophthora } \\
\text { thermophila C1 }\end{array}$ & $35.8 / 43$ & 5.23 & 2 & 23 & $15-25$ & GSSSG & 6 & MF362597 \\
\hline AnFaeA & Aspergillus niger & Pichia pastoris & $28.4 / 36$ & 4.21 & 1 & 0 & 89.6 & GHSLG & 7 & CAA70510 \\
\hline AcFaeB & Aspergillus clavatus & Pichia pastoris & $39.1 / 40$ & 6.23 & 4 & 1 & $\mathrm{n} / \mathrm{q}$ & GHSFG & 8 & jgi | Aspcl1 | 3045 \\
\hline AsFaeG & Aspergillus sydowii & Pichia pastoris & $57.6 / 60$ & 4.99 & 7 & 1 & 45.0 & GCSTG & 9 & jgi | Aspsy1 | 41271 \\
\hline AnFaeJ & Aspergillus niger & Pichia pastoris & $58.3 / 100$ & 4.88 & 9 & 2 & 61.2 & GCSTG & 9 & An15g05280 \\
\hline
\end{tabular}


Table 1. Cont

\begin{tabular}{|c|c|c|c|c|c|c|c|c|c|c|}
\hline $\begin{array}{l}\text { Enzyme } \\
\text { Sample }\end{array}$ & Origin & Expression & $\begin{array}{l}\text { Calculated/ } \\
\text { Observed } \\
\text { MW (kDa) }\end{array}$ & $\begin{array}{l}\text { Calculated } \\
\text { pI }\end{array}$ & $\begin{array}{c}\mathrm{N}- \\
\text { Glycosylation }\end{array}$ & $\begin{array}{c}O- \\
\text { Glycosylation }\end{array}$ & $\begin{array}{l}\text { FAE Content ( } \% \mathrm{~g} \\
\text { FAE } \mathrm{g}^{-1} \text { Protein) }\end{array}$ & $\begin{array}{l}\text { Nucleophilic } \\
\text { Elbow }\end{array}$ & $\mathrm{SF}^{\mathrm{a}}$ & Accession Number \\
\hline CsTan1 & Ceriporiopsis subvermispora & Pichia pastoris & $57.6 / 90$ & 4.67 & 7 & 4 & 48.5 & GCSTG & 9 & jgi | Cersu1 | 89153 \\
\hline AgFae2 & Aspergillus glaucus & Pichia pastoris & $53.2 / 75$ & 5.55 & 7 & 5 & 16.6 & GCSTG & 10 & OJJ88972 \\
\hline AnFaeE & Aspergillus niger & Pichia pastoris & $55.0 / 88$ & 4.11 & 8 & 14 & 71.2 & GCSTG & 10 & An11g01220 \\
\hline GmFae2 & Galerina marginata & Pichia pastoris & $57.0 / 59$ & 6.49 & 5 & 4 & $\mathrm{n} / \mathrm{q}$ & GESAG & 12 & jgi | Galma1 | 254175 \\
\hline AsFaeI & Aspergillus sydowii & Pichia pastoris & $59.4 / 55$ & 4.90 & 5 & 5 & $\mathrm{n} / \mathrm{q}$ & GESAG & 13 & jgi | Aspsy1 | 160668 \\
\hline
\end{tabular}

${ }^{a}$ Phylogenetic classification according to Dilokpimol et al. [18]; ${ }^{\mathrm{b}}$ the enzyme has a fungal cellulose binding domain $(\mathrm{fCBD} ; \mathrm{CBM} 1)^{\mathrm{c}}$ the enzymes share the same primary sequence; $\mathrm{n} / \mathrm{q}$.: not quantified. 
With $800 \mathrm{mM}$ prenol or 1-butanol, the highest transesterification rates were observed for Fae125 from T. wortmannii (SF5) (53-75 $\mathrm{mmol} \mathrm{g}^{-1} \mathrm{FAE} \mathrm{L}^{-1} \mathrm{~h}^{-1}$, respectively) and C1FaeB2 from Myceliophthora thermophila C1 (SF6) (54-56 mmol g ${ }^{-1} \mathrm{FAE} \mathrm{L}^{-1} \mathrm{~h}^{-1}$, respectively). The highest PFA yields were observed for C1FaeB2 (51.5\%), Fae125 (50.5\%), and C1FaeB1 (47.7\%) (Figure 2A). The highest PCA yields were observed for C1FaeB2 (SF6) (69.0\%), followed by Fae125 (SF5) (62.4\%) and C1FaeB1 (52.6\%) (Figure 2B). The highest BFA yields were observed for Fae125 (72.1\%), C1FaeB1 (57.9\%), and C1FaeB2 (53.4\%) (Figure 2C). For all aforementioned products, tannase-related FAEs (SF1-3, SF9-11) and choline esterase-related FAEs (SF12-13) showed almost undetectable (0.3-2\%) or no synthetic activity, with low background hydrolytic activity. Fae68 (SF1) from T. wortmannii was the only exception showing moderate to low yields for PFA or PCA and BFA $(21.9 \%$ or $45.2 \%$ and $9.2 \%$, respectively), while AnFaeA (SF7) from A. niger showed a PFA yield of $7.2 \%$ and BFA yield of $10.5 \%$. Selectivity was $>1$ (meaning that transesterification is higher than hydrolysis) only for Fae125, C1FaeB1 and C1FaeB2 for both products. In a previous work, PFA was synthesized by SF5 and 6 FAEs from M. thermophila $\mathrm{C} 1$, confirming that SF6 FAEs have higher specificity and increased yield, rate, and selectivity during transesterification with prenol than SF5 FAEs [11]. BFA has been synthesized by immobilized or free commercial enzymatic preparations, AnFaeA from A. niger, and StFaeC from Sporotrichum thermophile (syn. M. thermophila), resulting in good yields after the optimization of reaction conditions (up to $97 \%)[3,6,7]$ in agreement with the above observations.

With $800 \mathrm{mM}$ glycerol, the highest transesterification rates were observed for Fae125 (SF5) (90 $\mathrm{mmol} \mathrm{g}^{-1} \mathrm{FAE} \mathrm{L}^{-1} \mathrm{~h}^{-1}$ ) and AtFaeD from Aspergillus terreus (SF5) (83 $\mathrm{mmol} \mathrm{g}^{-1} \mathrm{FAE} \mathrm{L}^{-1} \mathrm{~h}^{-1}$ ) followed by C1FaeB2 (SF6) (61.9 $\mathrm{mmol} \mathrm{g}^{-1} \mathrm{FAE} \mathrm{L}^{-1} \mathrm{~h}^{-1}$ ) (Figure 2D). All evaluated enzymes synthesized GFA in varying yields. Generally, the acetyl xylan esterase-related FAEs (SF5-6) showed the highest GFA yields (18.8-86.4\%). In more detail, the highest yields were observed for Fae125 (SF5) (86.4\%) and AtFaeD (SF5) (85.5\%), followed by AsFaeE (SF6) (75.5\%) and C1FaeA1 (SF5) (73.5\%). FAEs C1FaeB1 (SF6) and C1FaeB2 (SF6) from M. thermophila C1 showed similar yields $(65.5 \%$ and $59.4 \%$, respectively) comparable to PFA and BFA synthesis. The lipase-related AnFaeA from A. niger (SF7) showed moderate yield (47.4\%), while the tannase-related FAEs (SF1-3, SF10-11) and choline esterase-related FAEs (SF12-13) exhibited considerably lower transesterification yields $(0.3-7.0 \%)$. Fae68 (SF1) showed a consistently lower yield with glycerol $(6.3 \%)$ when compared to PFA and BFA synthesis.

Two out of three SF9 FAEs have been characterized as enzymes with dual activity (FAE, tannase) according to Dilokpimol et al. [21]. They showed synthetic activity when glycerol was used as an acceptor, but not with the other alcohols. AcFaeB from Aspergillus clavatus (SF8), characterized as lipase, showed low GFA yield (1.6\%) but good selectivity (3.4). Selectivity was $>1$ during GFA synthesis for all evaluated fungal FAEs, except for members of SF1-2. In agreement with our findings, high yields resulting from FAE-catalyzed transesterification reactions with glycerol have been demonstrated previously. Glycerol sinapate has been synthesized by AnFaeA with MSA and glycerol in ionic liquids, yielding up to $76.7 \%$ [22]. Furthermore, FAE-PL from A. niger, purified from the enzymatic preparation Pectinase PL Amano, catalyzed the esterification of hydroxycinnamates with glycerol with high yields $(60-81 \%)$ in a solvent free system $[4,5]$.

\subsection{Synthesis of L-Arabinose Ferulate}

Enzymatic synthesis of AFA has so far been characterized by low yields due to limitations imposed by the insolubility of sugars in organic solvents and a predominance of hydrolysis over transesterification in the reactions at high enzyme loads [12]. In this study, the reaction conditions were adapted to halved enzyme load $\left(0.1 \mathrm{mg}\right.$ protein $\left.\mathrm{mL}^{-1}\right)$, reduced incubation time $(8 \mathrm{~h})$ and increased water content $(5.5 \% v / v)$ in order to maximize arabinose concentration assuring a representative screening of evaluated enzymes.

Synthesis of AFA at fixed conditions revealed that FAEs belonging to SF5 offered the highest transesterification yields (up to 20\%) (Figure 3). Moreover, the transesterification pattern of FAEs 
with the use of arabinose as an acceptor correlated well with that of prenol and glycerol $(0.9335$ and 0.9158, respectively), while it correlated less with 1-butanol (0.6153). Fae125 from T. wortmannii (SF5) transesterified L-arabinose at the highest rate among tested FAEs, while SF6 FAEs offered significantly low, but detectable, yields (1-5\%). The tannase-related Fae68 from T. wortmannii (SF1), AnFaeB from A. niger (SF1), FoFaeC from F. oxysporum (SF2), and the lipase-related AnFaeA from A. niger (SF7) offered almost undetectable transesterification yields (0.5-1.5\%).

The ability of acetyl xylan-related FAEs to efficiently transesterify L-arabinose is supported by our previous work where SF5 members homologously overexpressed in M. thermophila C1 showed increased catalytic efficiency and specificity for L-arabinose over SF6 members both at fixed and optimized conditions in detergentless microemulsions [12]. Furthermore, AFA has been synthesized in detergentless microemulsions by the SF1 type C TsFaeC from Talaromyces stipitatus in low yields $(21.2 \%$ after optimization of reaction conditions $[3,23]$ and StFaeC (acetyl xylan-related enzyme; possibly SF5) from Sporotrichum thermophile (syn. M. thermophila) (up to $45 \%$ after optimization of reaction conditions) [24] coming in agreement with our observations.

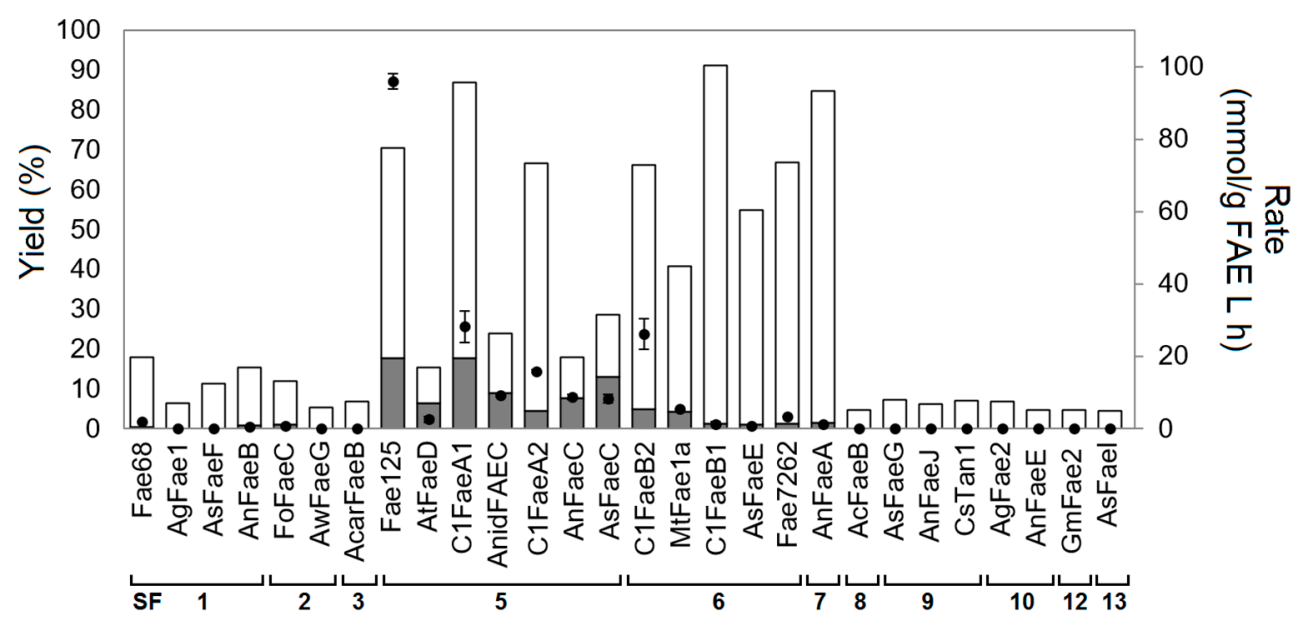

Figure 3. Synthesis of AFA. Reaction conditions: $50 \mathrm{mM} \mathrm{VFA,} 50 \mathrm{mM} \mathrm{L}$-arabinose, $0.1 \mathrm{mg}$ protein $\mathrm{mL}^{-1}$, 19.8:74.7:5.5 $v / v / v n$-hexane: $t$-butanol: buffer, $45^{\circ} \mathrm{C}$, no agitation, $8 \mathrm{~h}$ of incubation. Grey column: transesterification yield; white column: hydrolysis yield; black circle: specific rate of transesterification. The error bars represent the standard deviation between two duplicates.

\subsection{Sugar Ester Synthesis by Two SF5 FAES}

The two enzymes performing best in AFA synthesis (the type A FAEs C1FaeA1 and Fae125 belonging to SF5) were selected for use in synthetic reactions with a variety of sugar acceptors: pentoses, hexoses, disaccharides, sugar alcohols, and polysaccharides. Fae125 has high homology with C1FaeA1 (51\% identity; 67\% similarity; 1\% gaps). As presented in Figure 4, Fae125 had, on average, a 2.6-fold higher transesterification rate compared to C1FaeA1 at fixed conditions, while both enzymes had a very similar transesterification pattern (correlation coefficient 0.9611 ) between different acceptors. Both FAEs showed the highest yield/rate in descending order to sugar alcohols (sorbitol $\geq$ xylitol > mannitol) $>$ hexoses (fructose $>$ glucose, mannose, galactose) $\geq$ pentoses (arabinose $>$ xylose) $>$ disaccharides (sucrose $>$ maltose $>$ lactose, cellobiose). Selectivity $\geq 1$ was observed only when sugar alcohols were used as acceptors possibly due to the presence of two equivalent - $\mathrm{OH}$ groups and, perhaps, secondary groups that are accessible to transesterification, as in the case of glycerol (paragraph 2.1). The highest rates $\left(212 \mathrm{mmol} \mathrm{g}^{-1} \mathrm{FAE} \mathrm{L}^{-1} \mathrm{~h}^{-1}\right.$ for Fae125 and $80 \mathrm{mmol} \mathrm{g}^{-1} \mathrm{FAE} \mathrm{L}^{-1}$ $\mathrm{h}^{-1}$ for C1FaeA1) and yields (39\% for Fae125 and 50\% C1FaeA1) were observed during synthesis of sorbityl ferulate. Both enzymes showed no stereoselectivity for feruloylation of arabinose enantiomers, offering up to $20 \%$ conversion of VFA to L- or D-AFA. 

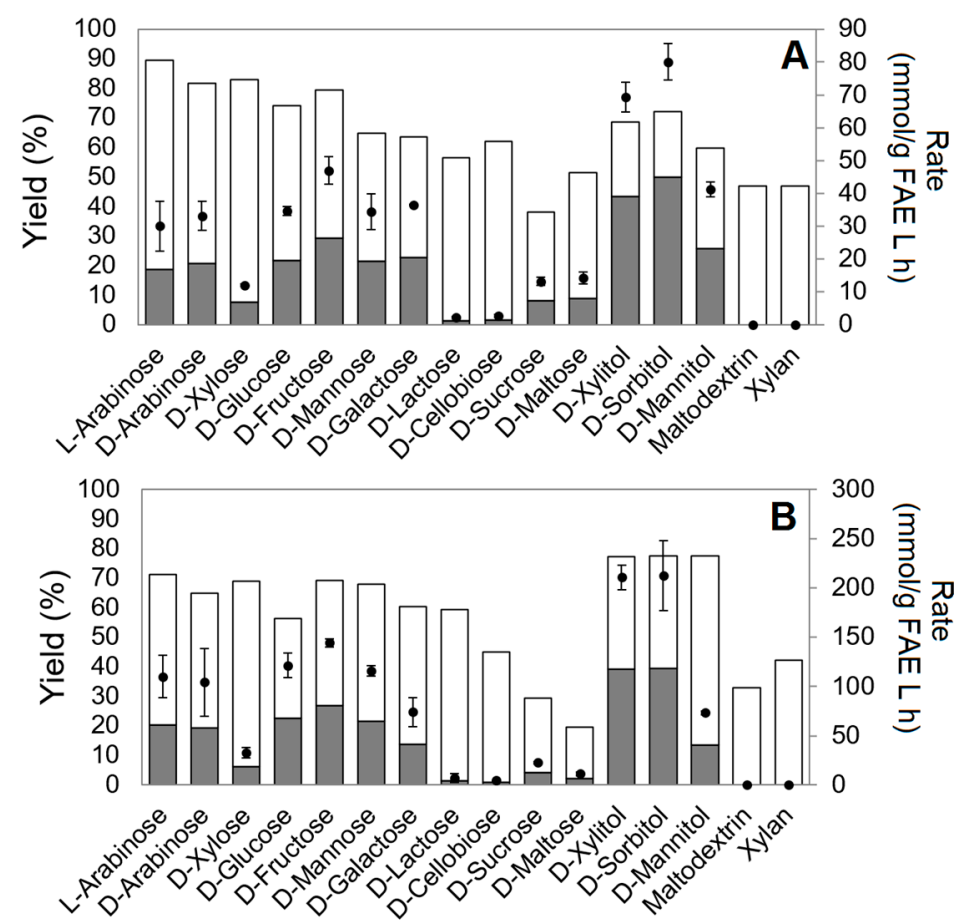

Figure 4. Synthesis of sugar esters by (A) C1FaeA1 and (B) Fae125. Reaction conditions: 50 mM VFA, $50 \mathrm{mM}$ sugar (except for $30 \mathrm{mg} / \mathrm{mL}$ xylan or maltodextrin), $0.1 \mathrm{mg}$ protein $\mathrm{mL}^{-1}, 19.8: 74.7: 5.5 \mathrm{v} / \mathrm{v} / \mathrm{v}$ $n$-hexane: $t$-butanol: buffer, $45^{\circ} \mathrm{C}$, no agitation, $8 \mathrm{~h}$ of incubation. Grey column: transesterification yield; white column: hydrolysis yield; black circle: specific rate of transesterification. The error bars represent the standard deviation between two duplicates.

During analysis of transesterification products, two peaks or three peaks (18.3-19.1 min) were detected for pentose and hexose substituted esters, respectively. We propose that these peaks reflect feruloylation of sugar anomers with slightly differing lipophilicity as it is generally accepted that sugar acylation occurs only at the primary $O-5$ hydroxyl group $[9,12,25]$. In the case of sugar alcohols, two major peaks (18.8-19.1 min) with similar lipophilicity, suggesting that feruloylation could have occurred as well in secondary hydroxyl groups of the polyol, and one additional distinctive peak with higher lipophilicity $(23.9 \mathrm{~min})$ were detected suggesting that the polyol could have undergone diferuloylation (Figure S2).

Although FAE-catalyzed synthesis of sugar esters has been reported previously, conclusions have not been clearly drawn regarding the preference of FAEs towards different sugars. Direct esterification yields of FA achieved by commercial preparations containing FAE activity with selected glycosides, di-, and oligosaccharides showed that esterifying activity among different acceptors was dependent on the enzymatic preparation [8,9]. StFaeC from S. thermophile (syn M. thermophila) catalyzed the synthesis of feruloylated arabino-oligosaccharides (with a different degree of polymerization) but no yields were quantified [23]. Est1 (SF12) from Pleurotus sapidus successfully synthesized feruloylated derivatives of glucose, fructose, galactose, sucrose, and maltose, but not lactose, via transesterification of MFA in sugar-saturated aqueous medium [25]. Yields were low, which is in accordance with our findings regarding AFA synthesis among tannase-related (SF1-3, 9-11) and choline esterase-related (SF12-13) phylogenetic subfamilies.

\subsection{Correlation with Phylogenetic Classification}

Screening of FAEs from different phylogenetic subfamilies (SF1-13) by transesterification of a ferulate donor (VFA) with alcohols of different lipophilicity $(800 \mathrm{mM}$ prenol, 1-butanol and glycerol, $3.2 \% v / v$ water) revealed that FAEs more closely related to acetyl xylan esterases (SF5-6) have increased 
synthetic potential. The most lipophilic product (PFA) was synthesized in highest yields unanimously by FAEs belonging to SF6, as well as by Fae125 from T. wortmannii belonging to SF5 (Figure 2A). When the more hydrophilic butanol was used as an acceptor (Figure 2C), the FAEs belonging to SF5 showed improved yields, although still lower than the SF6 FAEs. When the most hydrophilic acceptor glycerol was used, the SF5 FAEs followed by the SF6 FAEs showed the highest yields among all tested enzymes (Figure 2D). In contrast to other SF5 members, yield, and rate of Fae125 were consistently high regardless of the lipophilicity of acceptor. The lipase-related AnFaeA from A. niger (SF7) showed moderate yields while the tannase-related Fae68 from T. wortmannii was the only member of SF1 that showed moderately high synthetic yields. The discrepancy in the behavior of Fae68 (SF1) and Fae125 (SF5) among the 28 tested FAEs, indicates that these subfamilies might be further divided in the future, not only to support the ABCD classification, as suggested by Dilokpimol et al. [18], but also in order to adequately reflect the diversity in the transesterification function among these two subfamilies. In the case of AFA synthesis (50 mM L-arabinose, $5.5 \% v / v)$ ), it was confirmed that SF5 FAEs show higher preference in more hydrophilic acceptors. Furthermore, a screening of selected FAEs with synthetic potential (SF 1, 5, 6, and 7) at fixed acceptor concentration and water content $(50 \mathrm{mM}, 5.5 \% v / v)$ showed that, indeed, FAEs follow similar behavior in terms of preference in acceptors (glycerol $>$ L-arabinose $>$ 1-butanol > prenol) (Figure 5).

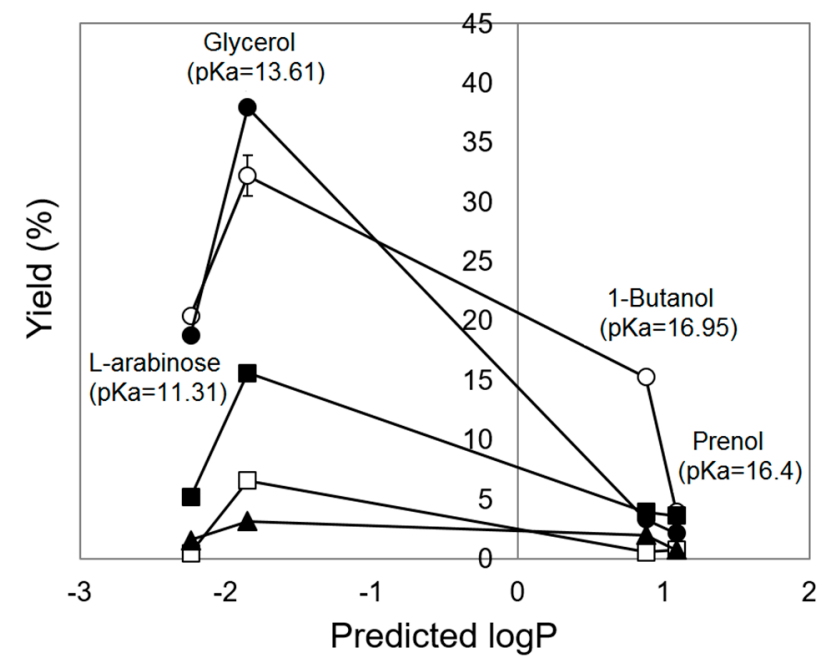

Figure 5. Effect of acceptor polarity on the transesterification yield of selected FAEs representing different phylogenetic subfamilies. Black circle: C1FaeA1 (SF5); white circle: Fae125 (SF5); black square: C1FaeB2 (SF6); white square: Fae68 (SF1); black triangle: AnFaeA (SF7). Reaction conditions: $50 \mathrm{mM}$ VFA, $50 \mathrm{mM}$ acceptor, $0.1 \mathrm{mg}$ protein $\mathrm{mL}^{-1}$, 19.8:74.7:5.5 $\mathrm{v} / \mathrm{v} / \mathrm{v} n$-hexane: $t$-butanol: buffer, $45{ }^{\circ} \mathrm{C}$, no agitation, $8 \mathrm{~h}$ of incubation. The error bars represent the standard deviation between two duplicate.

\subsection{Correlation with $A B C D$ Classification}

The transesterification of a ferulate and a caffeate donor (VFA and VCA) with prenol was used as the reaction for investigating the relationship between the synthetic potential of FAEs and their classification based on substrate specificity. The most studied FAE, type A AnFaeA from A. niger (SF7), showed no synthetic yield when a caffeate donor was used, aligning with the ABCD classification where type A FAEs prefer substrates with methoxy substitutions, such as MFA and MSA, and have no activity towards MCA. The type B FAEs Fae68 from T. wortmannii (SF1), C1FaeB2/MtFae1a, C1FaeB1 from M. thermophila (both SF6), and AsFaeE from A. sydowii (SF6) exhibited increased transesterification yields/rates against the caffeate donor compared to the ferulate one, while other type B FAEs, such as Fae7262 from T. wortmannii (SF6), showed similar yields (Figure 2A,B). This was in agreement with the $\mathrm{ABCD}$ classification, where type B FAEs prefer hydroxy substitutions, as found in M $p$ CA and MCA, 
but are active towards MFA. Type C AnFaeB from A. niger (SF1) and FoFaeC from F. oxysporum (SF2) showed low synthetic yields $(<2 \%)$ with both VFA and VCA.

Few discrepancies include type $C$ AtFaeD from A. terreus (SF5) and type C AnidFAEC from A. nidulans (SF5) that showed synthetic activity with VFA, but not VCA, although type C FAEs are expected to have a broader specificity and are active towards substrates containing methoxy and/or hydroxyl substitutions. Furthermore, the type A Fae125 from T. wortmannii (SF5), C1FaeA1 (SF5), and C1FaeA2 from $M$. thermophila (SF5) showed slightly higher yields during synthesis of PCA than PFA. In particular, Fae125 showed higher synthetic yield for PCA (62\%) compared to PFA $(50 \%)$, similar to type B FAEs, such as Fae68, C1FaeB2, and C1FaeB1, although it had higher hydrolytic activity towards MFA and MSA than towards MCA and MpCA (Table 2).

In addition to the partial agreement of the transesterification yields with the ABCD classification, there was no observed correlation between the synthetic and hydrolytic activities of evaluated enzymes. For instance, AsFaeF (SF1) and AsFaeI (SF13) from A. sydowii had high hydrolytic activities (Table 2), but they did not exhibit any synthetic activity (Figure 2). Similarly, among the C1-expressed FAEs, Fae68 (SF1) had the highest hydrolytic activity, but showed only moderate synthetic activity, while Fae125 had one of the lowest hydrolytic activities while being the most potent synthetic biocatalyst evaluated in this study.

Table 2. Relative hydrolytic activity (\%, determined as $\mathrm{U} \mathrm{mg}^{-1}$ protein) of FAEs against hydroxycinnamic acid substrates.

\begin{tabular}{|c|c|c|c|c|c|c|c|c|}
\hline \multirow{2}{*}{ Enzyme Sample } & \multirow{2}{*}{ Type } & \multicolumn{5}{|c|}{ Relative Hydrolytic Activity (\%) } & \multirow{2}{*}{$\mathrm{SF}^{\mathrm{a}}$} & \multirow{2}{*}{ Reference } \\
\hline & & MFA & MCA & MSA & $\mathbf{M} p \mathbf{C A}$ & $p$ NP-Fe & & \\
\hline \multicolumn{9}{|c|}{ Fungal FAEs } \\
\hline Fae68 & $\mathrm{B}$ & 4.10 & 3.39 & 0 & 5.84 & $\mathrm{n} / \mathrm{d}$ & 1 & This work \\
\hline AgFae1 & $\mathrm{C}$ & 0.031 & 0.047 & 0.005 & 0.020 & 0.025 & 1 & This work \\
\hline AsFaeF & B & 60.12 & 65.88 & 0 & 100 & 1.552 & 1 & {$[21]$} \\
\hline AnFaeB & B & 1.131 & 1.486 & 0 & 1.930 & 0.00074 & 1 & {$[21,26]$} \\
\hline FoFaeC & $\mathrm{C}$ & 0.247 & 0.389 & 0.013 & 0.457 & $\mathrm{n} / \mathrm{d}$ & 2 & {$[21,27]$ This work } \\
\hline AwFaeG & $\mathrm{n} / \mathrm{a}$ & 0.00012 & 0 & 0 & 0 & 0.0016 & 2 & {$[21]$} \\
\hline AcarFaeB & $\mathrm{n} / \mathrm{a}$ & 0 & 0.0024 & 0 & 0 & 0.0006 & 3 & [21] \\
\hline Fae125 & A & 0.059 & 0.024 & 0.047 & 0.023 & $\mathrm{n} / \mathrm{d}$ & 5 & This work \\
\hline AtFaeD & $\mathrm{C}$ & 0.00022 & 0.00007 & 0.00022 & 0.00011 & 0.0172 & 5 & {$[28]$} \\
\hline C1FaeA1 & $\mathrm{A}$ & 0.127 & 0.057 & 0.114 & 0.059 & $\mathrm{n} / \mathrm{d}$ & 5 & [29] \\
\hline AnidFAEC & C or D & 2.53 & 1.07 & 1.18 & 2.48 & 0.555 & 5 & [21] \\
\hline C1FaeA2 & $\mathrm{A} / \mathrm{B}$ & 0.076 & 0.045 & 0.031 & 0.064 & $\mathrm{n} / \mathrm{d}$ & 5 & [29] \\
\hline AnFaeC & C & 0.998 & 0.466 & 0.555 & 0.887 & $\mathrm{n} / \mathrm{d}$ & 5 & [30] \\
\hline AsFaeC & Cor D & 3.84 & 1.71 & 1.51 & 3.50 & 0.555 & 5 & [21] \\
\hline C1FaeB2 ${ }^{c}$ & B & 0.616 & 0.458 & 0.096 & 0.794 & $\mathrm{n} / \mathrm{d}$ & 6 & [29] \\
\hline MtFae1a ${ }^{c}$ & B & 0.0010 & 0.0056 & 0 & 0 & 0.060 & 6 & {$[21,31]$} \\
\hline C1FaeB1 & $\mathrm{B}$ & 0.596 & 1.50 & 0 & 0.981 & $\mathrm{n} / \mathrm{d}$ & 6 & [28] \\
\hline AsFaeE & C or D & 7.03 & 3.75 & 4.19 & 6.70 & 1.44 & 6 & [21] \\
\hline Fae7262 & B & 0.377 & 0.290 & 0 & 0.576 & $\mathrm{n} / \mathrm{d}$ & 6 & This work \\
\hline AnFaeA & $\mathrm{A}$ & 1.708 & 0 & 1.375 & 0 & 0.0015 & 7 & {$[21,32]$} \\
\hline $\mathrm{AcFaeB}^{\mathrm{b}}$ & $\mathrm{n} / \mathrm{a}$ & $\sim 0$ & $\sim 0$ & $\sim 0$ & $\sim 0$ & $\sim 0$ & 8 & [21] \\
\hline AsFaeG ${ }^{d}$ & $\mathrm{n} / \mathrm{a}$ & 0 & 0 & 0 & 0 & 0 & 9 & [21] \\
\hline AnFaeJ $^{\mathrm{d}}$ & $\mathrm{n} / \mathrm{a}$ & 0 & 0 & 1.52 & 0.149 & 0.0023 & 9 & [21] \\
\hline CsTan $1^{\mathrm{d}}$ & $\mathrm{n} / \mathrm{a}$ & 0 & 0 & 0 & 0 & 0 & 9 & [21] \\
\hline AgFae2 & $\mathrm{C}$ & 0.0019 & 0.0007 & 0.0019 & 0.0015 & 0.0077 & 10 & This work \\
\hline AnFaeE & $\mathrm{C}$ & 0.011 & 0.040 & 0.009 & 0.001 & $\mathrm{n} / \mathrm{d}$ & 10 & [21] \\
\hline GmFae2 & $\mathrm{n} / \mathrm{a}$ & 0 & 0 & 0 & 0 & 0.0007 & 12 & [21] \\
\hline AsFaeI & B & 58.85 & 64.22 & 0 & 98.56 & 1.353 & 13 & [21] \\
\hline
\end{tabular}

\footnotetext{
${ }^{a}$ Phylogenetic classification according to Dilokpimol et al. [18]; ${ }^{b}$ Lipase activity; ${ }^{c}$ same primary sequence;

$\mathrm{d}$ Tannase activity; $\mathrm{n} / \mathrm{a}$ : not applicable; $\mathrm{n} / \mathrm{d}$ : not determined in this study.
} 


\subsection{Factors Affecting Transesterification}

A challenge in understanding the factors that impact the selectivity of transesterification over hydrolysis in FAE-catalyzed reactions is the high diversity of this class of enzymes and the limited number of solved protein structures to date. A good correlation between the transesterification rate and the primary sequence homology of evaluated FAEs was observed (Table 3). In particular, the SF5 group accounting for seven members in this study, showed good correlation between the primary sequence identities of its members and the transesterification rates of different products, underlining that FAEs resembling Fae125 showed increased rates for all products. Furthermore, it was observed that the tannase-related SF1-2 and SF9-10 FAEs evaluated in this work share an identical and hydrophilic nucleophilic elbow (GCSTG). On the contrary, among SF6 FAEs only C1FaeB2 has a more lipophilic elbow (GFSSG) while all tested SF5 FAEs have lipophilic elbows such as Fae125 (GWSYG) (Table 1).

At a second level, homology modeling was employed as a tool for the identification of characteristics regarding the enzymes' surface environment, size of binding pocket, and docking of donor (VFA) that could possibly enable efficient transesterification. The study was focused on selected fungal FAEs that had at least $\geq 40 \%$ similarity with solved structures in the Protein Data Bank (PDB). Homology modeling was performed based on a template structure with high sequence identity. In particular, the tannase-related SF1-3 FAEs showed high homology with the FAE B (AoFaeB) from Aspergillus oryzae [33] while SF6 acetyl xylan related-FAEs showed homology with an acetyl xylan esterase from Aspergillus luchuensis [34]. The SF5 acetyl-xylan-related FAEs showed no significant homology with determined structures $(<30 \%)$, therefore, this intriguing group was not used for the prediction of surface properties and SMD simulations. The determined structure of the SF7 AnFaeA from A. niger (PDB ID: 1UWC) was also used in this study.

Estimations on the \% polarity and lipophilicity of the enzymes' surface showed that SF6 acetyl xylan-related FAEs are more lipophilic and non-polar molecules than tannase-related FAEs (SF1-2) (Table 4). Indeed, the SF6 Fae7262, C1FaeB1, and C1FaeB2 were among the less polar molecules (non-polar residues $47.8 \%, 47.0 \%$, and $44.2 \%$, respectively). Most importantly, the area around the catalytic serine was the least polar for C1FaeB1, and C1FaeB2 (56.9\% and 53.4\%), perhaps explaining the high transesterification yields for more non-polar acceptors (i.e., prenol). Among the tannase-related FAEs, only Fae68 from T. wortmannii had similar values around the active site (non-polar residues $48.2 \%$ ). Interestingly, this enzyme was also the only member that showed moderate transesterification potential. An increased percentage of non-polar and/or lipophilic amino-acids around the active site could attract alcohol molecules over water molecules, thereby enabling transesterification over hydrolysis. Furthermore, the polarity of lipase-related AnFaeA (SF7) was similar to that of the tannase-related FAEs. 
Table 3. Primary sequence homology between members of phylogenetic subfamilies SF1, SF5, SF6, and SF9 and correlation with transesterification rate.

\begin{tabular}{|c|c|c|c|c|c|c|c|c|c|c|c|}
\hline \multirow{2}{*}{$\mathrm{SF}^{\mathrm{a}}$} & \multirow{2}{*}{ Query } & \multirow{2}{*}{ Subject } & \multicolumn{5}{|c|}{ Sequence Alignment Results ( $p$ BLAST) } & \multicolumn{4}{|c|}{$\begin{array}{l}\text { Correlation between Primary Sequence } \\
\text { Identity and Transesterification Rate }\end{array}$} \\
\hline & & & Query Cover (\%) & Identities (\%) & Positives (\%) & Gaps (\%) & E-Value & PFA & BFA & GFA & AFA \\
\hline \multirow{3}{*}{1} & \multirow{3}{*}{ Fae68 } & AgFae1 & 96 & 57 & 74 & 3 & 0.0 & \multirow{3}{*}{0.9956} & \multirow{3}{*}{0.9933} & \multirow{3}{*}{0.9955} & \multirow{3}{*}{0.9833} \\
\hline & & AsFaeF & 96 & 54 & 71 & 3 & 0.0 & & & & \\
\hline & & AnFaeB & 97 & 52 & 71 & 3 & 0.0 & & & & \\
\hline \multirow{6}{*}{5} & \multirow{6}{*}{ Fae125 } & ATEG_Fae & 77 & 57 & 72 & 0 & $6 \times 10^{-109}$ & \multirow{6}{*}{0.9774} & \multirow{6}{*}{0.9866} & \multirow{6}{*}{0.8199} & \multirow{6}{*}{0.9170} \\
\hline & & C1FaeA1 & 82 & 51 & 67 & 1 & $2 \times 10^{-90}$ & & & & \\
\hline & & AnidFAEC & 77 & 46 & 63 & 6 & $7 \times 10^{-79}$ & & & & \\
\hline & & C1FaeA2 & 78 & 44 & 61 & 7 & $5 \times 10^{-75}$ & & & & \\
\hline & & AnFaeC & 77 & 44 & 61 & 6 & $6 \times 10^{-75}$ & & & & \\
\hline & & AsFaeC & 77 & 43 & 58 & 4 & $3 \times 10^{-73}$ & & & & \\
\hline \multirow{3}{*}{6} & \multirow{3}{*}{ C1FaeB2 } & C1FaeB1 & 100 & 68 & 81 & 0 & $6 \times 10^{-144}$ & \multirow{3}{*}{0.9044} & \multirow{3}{*}{0.7886} & \multirow{3}{*}{0.8741} & \multirow{3}{*}{0.8699} \\
\hline & & AsFaeE & 100 & 48 & 68 & 0 & $4 \times 10^{-99}$ & & & & \\
\hline & & Fae7262 & 99 & 47 & 64 & 0 & $1 \times 10^{-93}$ & & & & \\
\hline \multirow[b]{2}{*}{9} & \multirow[b]{2}{*}{ AsFaeG } & AnFaeJ & 99 & 46 & 64 & 2 & $7 \times 10^{-173}$ & \multirow[b]{2}{*}{0.6162} & \multirow[b]{2}{*}{0.2161} & \multirow[b]{2}{*}{0.9925} & \multirow[b]{2}{*}{-} \\
\hline & & CsTan1 & 93 & 37 & 56 & 4 & $1 \times 10^{-100}$ & & & & \\
\hline
\end{tabular}

${ }^{a}$ Phylogenetic classification according to Dilokpimol et al. [18]; ${ }^{\text {b }}$ Based on detected rates among different products (at $800 \mathrm{mM} / 50 \mathrm{mM}$ acceptor for aliphatic alcohols/arabinose). 
Table 4. Properties of SF1-2 and SF6-7 FAE-predicted structures.

\begin{tabular}{|c|c|c|c|c|c|c|c|c|c|c|c|}
\hline Enzyme & Fae68 & AgFae1 & AsFaeF & AnFaeB & FoFaeC & AwFaeG & C1FaeB2 & C1FaeB1 & Fae7262 & AsFaeE & $\mathrm{AnFaeA}^{\mathrm{a}}$ \\
\hline SF & 1 & 1 & 1 & 1 & 2 & 2 & 6 & 6 & 6 & 6 & 7 \\
\hline Protein size (kDa) & 57.7 & 55.5 & 55.4 & 55.5 & 56.1 & 55.9 & 30.5 & 30.2 & 31.2 & 30.2 & 28.4 \\
\hline Protein volume $\left(\AA^{3}\right)$ & 62,063 & 60,284 & 59,722 & 60,410 & 60,107 & 59,908 & 32,825 & 32,506 & 33,286 & 32,281 & 301,120 \\
\hline $\begin{array}{l}\text { Catalytic triad } \\
\text { (Ser-His-Asp) }\end{array}$ & $214-469-429$ & $187-440-400$ & $187-439-399$ & $185-437-397$ & $201-452-412$ & $190-442-402$ & $136-275-219$ & $137-277-221$ & $136-276-220$ & $137-277-221$ & $133-247-194$ \\
\hline \multicolumn{12}{|c|}{ Molecular Surface $\left(\AA^{2}\right)$} \\
\hline \multicolumn{12}{|c|}{ Protein } \\
\hline Lipophilic (\%) & 33.5 & 30.6 & 32.9 & 31.2 & 30.6 & 33.6 & 35.6 & 38.8 & 32.3 & 35.3 & 26.8 \\
\hline Non-polar (\%) & 40.0 & 36.9 & 39.8 & 38.0 & 38.3 & 40.6 & 44.2 & 47.0 & 47.8 & 43.6 & 32.3 \\
\hline Neutral (\%) & 42.1 & 41.9 & 36.4 & 42.9 & 35.4 & 39.1 & 44.2 & 37.9 & 54.2 & 38.3 & 48.5 \\
\hline Acidic (\%) & 11.4 & 11.6 & 14.6 & 13.1 & 12.7 & 12.6 & 11.5 & 8.6 & 6.0 & 16.1 & 16.4 \\
\hline Basic (\%) & 12.7 & 15.5 & 15.5 & 14.3 & 20.9 & 14.5 & 8.3 & 14.3 & 7.2 & 9.9 & 8.1 \\
\hline \multicolumn{12}{|c|}{ Distance $<15 \AA$ Around the catalytic serine } \\
\hline Lipophilic (\%) & 38.9 & 30.4 & 36.2 & 26.4 & 32.7 & 29.2 & 45.4 & 43.7 & 33.5 & 43.8 & 30.2 \\
\hline Non-polar (\%) & 48.2 & 38.8 & 43.6 & 38.9 & 43.7 & 38.8 & 56.9 & 53.4 & 41.5 & 51.5 & 37.3 \\
\hline Neutral (\%) & 42.1 & 49.6 & 43.5 & 49.3 & 43.3 & 46.4 & 47.0 & 38.2 & 52.9 & 36.2 & 44.5 \\
\hline Acidic (\%) & 8.2 & 7.2 & 11.4 & 14.2 & 9.7 & 10.3 & 5.4 & 3.8 & 4.7 & 6.3 & 12.7 \\
\hline Basic (\%) & 10.0 & 12.2 & 8.2 & 9.5 & 13.4 & 13.4 & 6.7 & 13.6 & 8.4 & 13.2 & 11.9 \\
\hline \multicolumn{12}{|c|}{ Lid $^{\mathrm{b}}$} \\
\hline Lipophilic (\%) & 39.2 & 33.5 & 38.1 & 37.7 & 36.9 & 37.0 & & & & & 16.4 \\
\hline Non-polar (\%) & 44.7 & 38.1 & 44.4 & 44.7 & 45.5 & 44.1 & & & & & 27.6 \\
\hline Neutral (\%) & 39.9 & 43.7 & 35.9 & 38.0 & 37.8 & 41.5 & - & - & - & - & 41.3 \\
\hline Acidic (\%) & 11.9 & 7.8 & 10.8 & 14.1 & 12.2 & 8.6 & & & & & 24.1 \\
\hline Basic (\%) & 8.6 & 15.6 & 14.6 & 9.8 & 12.7 & 12.5 & & & & & 1.6 \\
\hline
\end{tabular}

${ }^{a}$ Determined structure; PDB ID: 1UWC; ${ }^{\text {b }}$ As described by Suzuki et al. [26]. 
In terms of size, the tannase-related FAEs are larger molecules than acetyl xylan-related and lipase-related FAEs. Moreover, the catalytic triad (Ser-His-Asp) and the binding pocket of tannase-related FAEs is narrower and confined in a deeper cavity, while for acetyl xylan-related FAEs is predicted to be more "exposed" and wider (Figure 6). This could allow flexibility and stabilization of donors in favorable conformations for transesterification, which was confirmed by SMD simulation using VFA as the ligand (Table 5). It was shown that, in the case of SF6 acetyl xylan-related FAEs, the vinyl moiety was stabilized in the vicinity of lipophilic residues, such as Pro or Leu. In the case of tannase-related FAEs, the vinyl moiety could be stabilized either in a hydrophilic area and in particular by Gly residues or in a lipophilic area by Leu residues. In the case of Fae68, the cluster resulting in catalytic orientation represented the vinyl moiety in the vicinity to lipophilic Ile residues, while in the case of other SF1 and 2 FAEs, the vinyl moiety was in the vicinity of hydrophilic Gly residues. For AnFaeA (SF7), the moiety is stabilized in a hydrophilic area and, in particular, by residue Thr68. Although AnFaeA is a more polar molecule, the moderate transesterification yields can be attributed to its accessible binding cavity and an adequate ratio of polar/apolar residues around the catalytic serine.
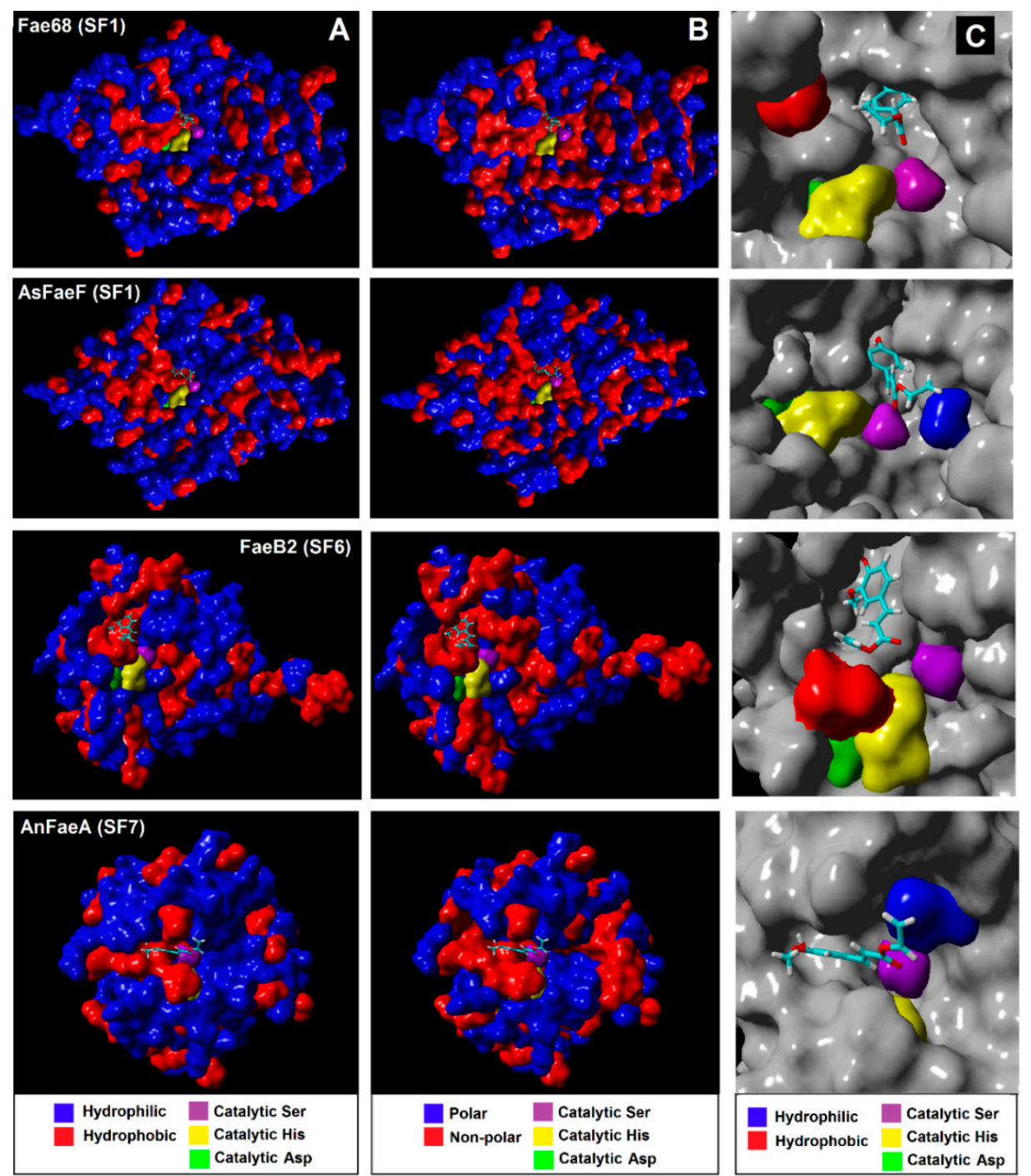

Figure 6. Predicted surface (A) lipophilicity (B) polarity of selected FAEs and (C) docked VFA inside the active site of selected FAEs. Homology models built by YASARA Structure (YASARA Biosciences $\mathrm{GmbH}$, Vienna, Austria) (SF1, 2, and 6 FAEs) and the solved structure of AnFaeA (PDB ID: 1UWC) were used for SMD simulations. 
Table 5. Results of docking of ligands on the predicted structure of selected fungal FAEs (SF1-3 and SF6-7) at a catalytic orientation.

\begin{tabular}{|c|c|c|c|c|c|c|}
\hline Receptor & $\mathrm{SF}^{\mathrm{a}}$ & $\begin{array}{l}\text { Mean Binding } \\
\text { Energy of Cluster } \\
\text { (kcal/mol) }\end{array}$ & $\begin{array}{l}\text { Highest Binding } \\
\text { Energy in Cluster } \\
\text { (kcal/mol) }\end{array}$ & Distance $^{b}$ & $\begin{array}{l}\text { Genetic } \\
\text { Runs in } \\
\text { Cluster }^{c}\end{array}$ & $\begin{array}{c}\text { Residue(s) in } \\
\text { Vicinity with Vinyl } \\
\text { Moiety in Cluster }\end{array}$ \\
\hline Fae68 & \multirow{4}{*}{1} & $6.0457 \pm 0.3754$ & 6.5580 & 2.823 & 3 & Ile358 \\
\hline AgFae1 & & $4.6875 \pm 0.2963$ & 5.3330 & 3.814 & 15 & Gly108 \\
\hline AsFaeF & & $5.5160 \pm 0.1797$ & 5.7610 & 2.842 & 3 & Gly108 \\
\hline AnFaeB & & $5.1805 \pm 0.1125$ & 5.2930 & 2.745 & 2 & Gly106 \\
\hline \multirow{2}{*}{$\begin{array}{c}\text { FoFaeC } \\
\text { AwFaeG }\end{array}$} & \multirow[b]{2}{*}{2} & $5.6489 \pm 0.3975$ & 6.4670 & 4.188 & 8 & Gly122 \\
\hline & & $5.6604 \pm 0.4224$ & 6.3690 & 2.953 & 12 & Gly111 \\
\hline \multirow{2}{*}{ C1FaeB1 } & \multirow{6}{*}{6} & $4.9831 \pm 0.2644$ & 5.3670 & 2.955 & 8 & Pro57 \\
\hline & & $4.7887 \pm 0.2200$ & 5.0730 & 3.968 & 3 & Leu223 \\
\hline \multirow{2}{*}{ C1FaeB2 } & & $5.2065 \pm 0.7067$ & 6.1220 & 3.969 & 10 & Leu221 \\
\hline & & $4.6880 \pm 0.0000$ & 4.6880 & 2.567 & 1 & Pro56 \\
\hline Fae7262 & & $4.8974 \pm 0.1512$ & 5.1510 & 4.387 & 5 & Pro56 \\
\hline AsFaeE & & $4.7585 \pm 0.1881$ & 4.9000 & 2.978 & 4 & Leu59 \\
\hline AnFaeA & 7 & $5.8980 \pm 0.6567$ & 6.7200 & 5.767 & 4 & Thr68 \\
\hline
\end{tabular}

${ }^{a}$ According to Dilokpimol et al. [18]; ${ }^{b}$ Distance between carbonyl carbon of ligand and catalytic serine of receptor;

${ }^{c}$ Total number of genetic runs is 25 .

Lastly, the nature of the acceptor is an important factor for transesterification. Synthetic reactions at fixed conditions $\left(5.5 \% \mathrm{v} / \mathrm{v}, 8 \mathrm{~h}, 0.1 \mathrm{mg} \mathrm{FAE} \mathrm{mL}^{-1}\right.$ ) for all tested acceptors (prenol, 1-butanol, glycerol, and L-arabinose) catalyzed by selected FAEs SF1, 5, 6, and 7 (Figure 5), showed that all FAEs exhibited increased yield in descending order of glycerol $>$ L-arabinose $>1$-butanol $>$ prenol. As previously discussed, FAEs generally showed a preference for more hydrophilic acceptors. The high yields for glycerol can be attributed to the presence of two equivalent - $\mathrm{OH}$ groups and a secondary $-\mathrm{OH}$ group that are bound for substitution and its smallest molecule volume among the above $\left(65.22 \AA^{3}\right)$. On the contrary, although increased yields would be expected for a highly hydrophilic and natural-like acceptor, such as L-arabinose, the limited obtained yields could be attributed to the fact that it can be substituted only at the $O-5$ position, has reduced solubility in low water content systems and is the bulkiest molecule $\left(98.45 \AA^{3}\right)$, possibly resulting in steric hindrances.

To sum up, the selectivity of enzymes towards transesterification is defined by enzyme-related characteristics and process-related characteristics. Regarding the enzyme, there are indications that (1) the size of the binding cavity, (2) the accessibility of the binding cavity by the acceptor, and (3) the active site surface environment seem to play important roles for efficient transesterification. The above are translated into phylogenetic characteristics of each subfamily. Efforts should focus on the determination of structures with high synthetic potential, such as SF5 and 6 FAEs, in order to further highlight the structural characteristics that aid synthetic reactions and identify properties that allow the preference of SF5 FAEs to transesterify sugars in higher yields and the ability of SF6 FAEs to transesterify with more lipophilic acceptors.

Regarding the reaction system, (1) the system composition (microemulsions, one phase, two phase single solvent), (2) the solubility of the substrates (donor and acceptor), (3) the nature of the acceptor (volume, lipophilicity, number of $-\mathrm{OH}$ groups accessible for transesterification), and (4) the distribution of acceptor in the reaction medium are important for increased selectivity. Detergentless microemulsions are an attractive system for transesterification, as the enzyme is enclosed in water micro-droplets and is protected from inactivation. This, however, requires increased concentrations of alcohol acceptors to be introduced in the organic phase of the microemulsions in order to ensure increased contact with the acceptor in the interface of the micro droplet compared to a single solvent water miscible system. Moreover, it favors side-hydrolysis as water molecules inside the micro droplet are more accessible than the alcohol acceptor that is present in the organic phase. On the other hand, the solubility of substrates is crucial for efficient transesterification, as it is commonly accepted that the acceptor should be in excess compared to the donor. In the case of sugars and, in particular, 
L-arabinose, the insolubility poses severe limitations that are reflected in reduced yields and selectivity. Furthermore, the distribution of acceptor in the microemulsions is different in the case of alcohols and sugars, as donor and acceptor are mainly present in the organic phase in the case of alcohols, while the sugar acceptor is present in the water phase of the system.

\section{Materials and Methods}

\subsection{Production of Enzymes in Myceliophthora thermophila C1}

The M. thermophila $\mathrm{C} 1$ genes encoding the FAEs C1FaeA1, C1FaeA2, C1FaeB1, and C1FaeB2, were over-expressed individually in designated $\mathrm{C} 1$ strains with a low-cellulase production background $[29,35]$. Genomic DNA sequences encoding the three putative feruloyl esterases, Fae68, Fae7262, and Fae125, were synthesized (GeneArt, Regensburg, Germany) and cloned into a transformation vector as previously described [29]. In each case, the resulting expression cassette containing the gene of interest under the control of a strong promoter was co-transformed with a selection marker in a $\mathrm{C} 1$ production strain. For enzyme characterization, the production strains were grown aerobically in a fed-batch system in minimal medium supplemented with trace elements [36]. After fermentation, the broth was centrifuged $\left(15,000 \times g\right.$ for $\left.1 \mathrm{~h}, 4{ }^{\circ} \mathrm{C}\right)$ and the cell-free broth was concentrated and dialyzed to $10 \mathrm{mM}$ phosphate buffer $\mathrm{pH}$ 6.5. Samples were subsequently freeze-dried for storage.

\subsection{Production of Enzymes in Pichia pastoris}

Production of MtFaela and FoFaeC was done as described previously [32,33]. P. pastoris transformants containing FAEs from Aspergillus species, Ceriporiopsis subvermispora, and Galerina marginata were grown according to previous reports [26,28,30,32]. Induction was done for $96 \mathrm{~h}$ at $28^{\circ} \mathrm{C}$ with methanol being supplemented to $0.5 \%(v / v)$ every $24 \mathrm{~h}$. Culture supernatants were harvested $\left(4000 \times g, 4{ }^{\circ} \mathrm{C}, 20 \mathrm{~min}\right)$, filtered ( $0.22 \mu \mathrm{m}$; Merck Millipore, Darmstadt, Germany), concentrated (10 kDa cut off; Merck Millipore, Germany), and stored at $-20^{\circ} \mathrm{C}$ prior to further analysis.

\subsection{Enzymatic Assays}

Prior to transesterification reactions, the enzymatic samples were buffer-exchanged with $100 \mathrm{mM}$ MOPS-NaOH $\mathrm{pH}$ 6.0. The protein concentration of each sample was determined with the Pierce BCA Protein Assay kit (ThermoFisher Scientific, Waltham, MA, USA). Following, the FAE content ( $\% w / w$ FAE/total protein) of each enzymatic sample was estimated by SDS-PAGE and subsequent quantification was done by a densitometric method using JustTLC software (Sweday, Lund, Sweden) as presented in Table 1. Enzymatic assays for the detection of hydrolytic activity were done as described by Dilokpimol et al. [21].

\subsection{Transesterification Reactions}

Synthesis of hydroxycinnamic acid esters was evaluated in a ternary system forming detergentless microemulsions without agitation at $45{ }^{\circ} \mathrm{C}$ and $500 \mu \mathrm{L}$ total volume in a temperature-controlled water bath. Aliphatic esters synthesis was done in 53.4:43.4:3.2 v/v/v n-hexane: $t$-butanol: $100 \mathrm{mM}$ MOPS-NaOH pH 6.0 using $50 \mathrm{mM}$ donor (VFA or VCA, provided by Taros Chemicals $\mathrm{GmbH}$ and Co. KG, Dortmund, Germany), $200 \mathrm{mM}$ or $800 \mathrm{mM}$ acceptor (prenol, glycerol or 1-butanol, $\geq 99 \%$ ), and $0.2 \mathrm{mg}$ protein $\mathrm{mL}^{-1}$ for $24 \mathrm{~h}$. In more detail, an adequate amount of donor was diluted in a mixture of $n$-hexane $(<0.02 \%$ water) and $t$-butanol (anhydrous, $\geq 99.5 \%$ ), followed by the addition of acceptor under vigorous shaking. Each reaction was initiated by introducing the enzyme in the form of a concentrated stock solution in buffer, followed by vigorous shaking until a stable one-phase solution was obtained. Synthesis of sugar esters was done in 19.8:74.7:5.5 $v / v / v n$-hexane: $t$-butanol: $100 \mathrm{mM}$ MOPS-NaOH pH 6.0 using $50 \mathrm{mM}$ donor and acceptor $(50 \mathrm{mM}$ L-arabinose or other sugars, except for $30 \mathrm{mg} / \mathrm{mL}$ xylan/maltodextrin) and $0.1 \mathrm{mg}$ protein $\mathrm{mL}^{-1}$ for $8 \mathrm{~h}$. The acceptor and enzyme were 
introduced in the mixture of donor and solvent in the form of concentrated stock solution in buffer. All FAEs were tested for the synthesis of L-arabinose ferulate (AFA) while the two most promising FAEs were subsequently used for synthesis of a variety of sugar esters.

The effect of acceptor polarity on the transesterification yield was studied at $50 \mathrm{mM}$ donor and $50 \mathrm{mM}$ acceptor in 19.8:74.7:5.5 $v / v / v n$-hexane: $t$-butanol: $100 \mathrm{mM}$ MOPS-NaOH pH 6.0 and $0.1 \mathrm{mg}$ protein $\mathrm{mL}^{-1}$ for $8 \mathrm{~h}$. At the end of the incubation, a sample $(10 \mu \mathrm{L})$ was withdrawn from the reaction mixture, diluted 100-fold in acetonitrile $(990 \mu \mathrm{L})$ for enzyme inactivation, and subjected to HPLC analysis. All reactions were performed in duplicate accompanied by blank samples containing buffer instead of enzyme. No substrate consumption could be detected in the absence of esterases.

\subsection{Quantitative Analysis of Hydroxycinnamates}

Analysis of hydroxycinnamates was performed by HPLC on a 100-5 C18 Nucleosil column $(250 \times 4.6 \mathrm{~mm})$ (Macherey Nagel, Düren, Germany). Elution was conducted with a linear gradient method using acetonitrile (solvent $\mathrm{A}$ ) and water (solvent $\mathrm{B}$ ) at $0.6 \mathrm{~mL} \mathrm{~min}^{-1}$ and room temperature $\left(20^{\circ} \mathrm{C}\right)$. Total running time was $50 \mathrm{~min}$, during which the following proportions of solvent A were used: $0-100 \%$ (linear gradient), $0-35 \mathrm{~min} ; 100 \%$ (isocratic), 35-38 min; $0 \%$ (isocratic), 38-50 min. Total retention times were the following: $10.4 \mathrm{~min}(\mathrm{CA})<13.1 \mathrm{~min}(\mathrm{FA})<18.3-23.9 \mathrm{~min}$ (sugar esters), 18.7 (AFA) $<20.6 \mathrm{~min}(\mathrm{GFA})<27.2 \mathrm{~min}(\mathrm{VCA})<29.8 \mathrm{~min}(\mathrm{VFA})<30.5 \mathrm{~min}(\mathrm{PCA})<32.4 \mathrm{~min}(\mathrm{BFA})<$ $32.9 \mathrm{~min}$ (PFA). Detection was achieved by a PerkinElmer Flexar UV/Vis detector at $300 \mathrm{~nm}$ based on calibration curves prepared using standard solutions of the detected compounds in acetonitrile. The transesterification yield was calculated as the molar amount of generated product compared to the initial molar amount of donor (VFA or VCA), expressed as percentage. Accordingly, the hydrolysis yield was calculated as the molar amount of hydrolysate (FA or CA) compared to the initial amount of donor, expressed as a percentage. The transesterification rate was calculated as the molar concentration of the generated product per hour per g FAE of the enzymatic sample. The selectivity was defined as the molar amount of the generated transesterification product divided by the molar amount of hydrolysate.

\subsection{Bioinformatic Tools}

Signal peptides were predicted using SignalP 4.1 (http:/ / www.cbs.dtu.dk/services/SignalP) [37]. The theoretical molecular weight (MW) and isoelectic point $(\mathrm{pI})$ values were calculated by the ExPASy-ProtParam tool (http://www.expasy.ch/tools/protparam.html) [38]. Glycosylation sites were predicted using NetNGlyc 1.0 (http:/ / www.cbs.dtu.dk/services/NetNGlyc) and NetOGlyc 4.0 (http://www.cbs.dtu.dk/services/NetOGlyc) [39]. The above properties are presented in Table 1. Sequence comparison was done by $p$ BLAST. Phylogenetic analysis was performed according to Dilokpimol et al. [18,21]. Predicted structures of FAEs were built by YASARA Structure via homology modeling [40]. For each enzyme, the exported model with highest Z-scores was used for analysis. All predicted structure models that were used for prediction of surface properties and as receptor SMD simulations, passed quality tests (Z-score > -3) (Table S1; Figures S3 and S4).

Prior to docking and surface visualization, the predicted structures of receptors were cleaned, glycosylation sites were removed, and their hydrogen bond network was optimized. The structures were subsequently energy minimized (based on the AMBER14 force field), while the $\mathrm{p} K_{\mathrm{a}}$ values of the ionisable groups were predicted and were assigned protonation states based on $\mathrm{pH} 6.0,0.9 \% \mathrm{NaCl}$. VFA as the ligand was designed, cleaned, and its geometry was optimized in YASARA Structure. A simulation cell was built around the catalytic serine of each enzyme $(20 \times 20 \times 20)$, large enough to contain the ligand and to allow flexibility for acquiring different orientations. Docking of the ligand was done by Autodock VINA [41] performing 25 runs per simulation on one monomer of receptor (enzyme). Results were evaluated based on the resulting binding energy (more positive energies indicate stronger binding and negative energies mean no binding), the number of genetic runs per cluster, the orientation of the ligand per cluster, and the distance of carbonyl carbon from the catalytic serine of the cluster resulting in a catalytic orientation. This was determined according to 
Suzuki et al. [33] based on the co-crystallization of FA with AnFaeA from Aspergillus niger [42] where the hydroxycinnamate moiety of the ligand is placed in the binding pocket while the substitution is extending outside the pocket. Ligand-receptor complexes were visualized and surface properties were calculated by YASARA [43].

\section{Conclusions}

The discovery of novel biocatalysts for the synthesis of bioactive ferulate derivatives offering high yield and selectivity is often challenging. In this work, we demonstrated screening conditions that allow the detection of the synthetic abilities of FAEs with varying synthetic potential and the identification of enzymes with increased specificity, excluding possible inactivation effects and resulting in low by-product formation. It was revealed that specific phylogenetic characteristics indicate fungal biocatalysts more prone to synthesis. The vast majority of FAEs preferred more hydrophilic alcohol acceptors (glycerol > 1-butanol > prenol), whereas sugar synthesis is dominated by strong limitations due to acceptor solubility restraints and large size. We suggest that future work should focus on the structural determination of potent biocatalysts showing low homology to currently-solved structures.

Supplementary Materials: The following are available online at http:/ /www.mdpi.com/2073-4344/8/6/242/s1, Figure S1: Synthesis of (A) PFA (B) PCA (C) BFA and (D) GFA. Reaction conditions: $50 \mathrm{mM}$ donor (VFA or VCA), $200 \mathrm{mM}$ acceptor, $0.2 \mathrm{mg}$ protein $\mathrm{mL}^{-1}$, 53.4: $43.4: 3.2 \mathrm{v} / \mathrm{v} / \mathrm{v} n$-hexane: $t$-butanol: buffer, $45^{\circ} \mathrm{C}$, no agitation, $24 \mathrm{~h}$ of incubation. Grey column: transesterification yield; White column: hydrolysis yield; Black circle: Specific rate of transesterification. The error bars represent the standard deviation between two duplicates, Figure S2: HPLC chromatograms for (A) GFA (B) AFA (C) Glycosyl ferulate and (D) Sorbityl ferulate synthesis, Figure S3: Predicted structures for SF1-2 FAEs obtained by homology modeling using YASARA Structure (YASARA Biosciences $\mathrm{GmbH}$, Vienna, Austria). Magenta: Catalytic serine; Yellow: Catalytic Histidine; Green: Catalytic Aspartate; Red: Predicted glycosylation; Blue: $\mathrm{Ca}^{+2}$, Figure S4: Predicted structures for SF6 FAEs obtained by homology modeling using YASARA Structure (YASARA Biosciences GmbH, Vienna, Austria). Magenta: Catalytic serine; Yellow: Catalytic Histidine; Green: Catalytic Aspartate; Red: Predicted glycosylation; Blue: $\mathrm{Na}^{+}$, Table S1: Structure templates and quality test results on the best fully-refined models exported by YASARA Structure for selected fungal FAEs (SF1-2 and SF6).

Author Contributions: Luleå University of Technology (Sweden) designed and performed the transesterification experiments, performed the homology modeling, and small molecule docking simulations, produced and characterized FoFaeC, analyzed the data, and wrote the manuscript. Westerdijk Fungal Biodiversity Institute (The Netherlands) performed the phylogenetic analysis of fungal FAEs. The following institutions produced enzymes and characterized their hydrolytic activities: Westerdijk Fungal Biodiversity Institute (The Netherlands): AnidFAEC, AnFaeC, AsFaeC, AsFaeE, AsFaeG, AsFaeI, and AsFaeF, DuPont Industrial Biosciences (The Netherlands): C1FaeA1, C1FaeA2, C1FaeB1, C1FaeB2, Fae68, Fae7262, and Fae125, University of Helsinki (Finland): AnFaeA, AnFaeB, AtFaeD, CsTan1, AnFaeJ, and AnFaeE, University of Naples (Italy): MtFae1a, AwFaeG, AcarFaeB, and GmFae2, Chalmers University of Technology (Sweden): AgFae1 and AgFae2. University of Münster (Germany) produced AsFaeF. Taros Chemicals GmbH and Co. KG (Germany) provided substrates (VFA, VCA, and $p \mathrm{NP}-\mathrm{Fe}$ ). All authors reviewed and approved the manuscript.

Acknowledgments: This work was supported by the European Union, grant agreement no: 613868 (OPTIBIOCAT).

Conflicts of Interest: The authors declare no conflict of interest.

\section{References}

1. Giuliani, S.; Piana, C.; Setti, L.; Hochkoeppler, A.; Pifferi, P.G.; Williamson, G.; Faulds, C.B. Synthesis of pentylferulate by feruloyl esterase from Aspergillus niger using water-in-oil microemulsions. Biotechnol. Lett. 2001, 23, 325-330. [CrossRef]

2. Topakas, E.; Stamatis, H.; Biely, P.; Kekos, D.; Macris, B.J.; Christakopoulos, P. Purification and characterization of a feruloyl esterase from Fusarium oxysporum catalyzing esterification of phenolic acids in ternary water-organic solvent mixtures. J. Biotechnol. 2003, 102, 33-44. [CrossRef]

3. Vafiadi, C.; Topakas, E.; Wong, K.K.Y.; Suckling, I.D.; Christakopoulos, P. Mapping the hydrolytic and synthetic selectivity of a type $\mathrm{C}$ feruloyl esterase (StFaeC) from Sporotrichum thermophile using alkyl ferulates. Tetrahedron Asymmetry 2005, 16, 373-379. [CrossRef] 
4. Tsuchiyama, M.; Sakamoto, T.; Fujita, T.; Murata, S.; Kawasaki, H. Esterification of ferulic acid with polyols using a ferulic acid esterase from Aspergillus niger. Biochim. Biophys. Acta 2006, 7, 1071-1079. [CrossRef] [PubMed]

5. Tsuchiyama, M.; Sakamoto, T.; Tanimori, S.; Murata, S.; Kawasaki, H. Enzymatic synthesis of hydroxycinnamic acid glycerol esters using type A feruloyl esterase from Aspergillus niger. Biosci. Biotechnol. Biochem. 2007, 71, 2606-2609. [CrossRef] [PubMed]

6. Vafiadi, C.; Topakas, E.; Christakopoulos, P. Preparation of multipurpose cross-linked enzyme aggregates and their application to production of alkyl ferulates. J. Mol. Catal. B Enzym. 2008, 54, 35-41. [CrossRef]

7. Vafiadi, C.; Topakas, E.; Alissandratos, A.; Faulds, C.B.; Christakopoulos, P. Enzymatic synthesis of butyl hydroxycinnamates and their inhibitory effect on LDL-oxidation. J. Biotechnol. 2008, 133, 497-504. [CrossRef] [PubMed]

8. Couto, J.; Karboune, S.; Mathew, R. Regioselective synthesis of feruloylated glycosides using the feruloyl esterase expressed in selected commercial multi-enzymatic preparations as biocatalysts. Biocatal. Biotransform. 2010, 28, 235-244. [CrossRef]

9. Couto, J.; St-Louis, R.; Karboune, S. Optimization of feruloyl esterase-catalyzed synthesis of feruloylated oligosaccharides by response face methodology. J. Mol. Catal. B Enzym. 2011, 73, 53-62. [CrossRef]

10. Kikugawa, M.; Tsuchiyama, M.; Kai, K.; Sakamoto, T. Synthesis of highly water-soluble feruloyl diglycerols by esterification of an Aspergillus niger feruloyl esterase. Appl. Microbiol. Biotechnol. 2012, 95, 615-622. [CrossRef] [PubMed]

11. Antonopoulou, I.; Leonov, L.; Jütten, P.; Cerullo, G.; Faraco, V.; Papadopoulou, A.; Kletsas, D.; Ralli, M.; Rova, U.; Christakopoulos, P. Optimized synthesis of novel prenyl ferulate performed by feruloyl esterases from Myceliophthora thermophila in microemulsions. Appl. Microbiol. Biotechnol. 2017, 101, 3213-3226. [CrossRef] [PubMed]

12. Antonopoulou, I.; Papadopoulou, A.; Iancu, L.; Cerullo, G.; Ralli, M.; Jütten, P.; Piechot, A.; Faraco, V.; Kletsas, D.; Rova, U.; et al. Optimization of enzymatic synthesis of L-arabinose ferulate catalyzed by feruloyl esterases from Myceliophthora thermophila in detergentless microemulsions and assessment of its antioxidant and cytotoxicity activities. Process Biochem. 2018, 101, 3213-3226. [CrossRef]

13. Faulds, C.B.; Perez-Boada, M.; Martinez, A.T. Influence of organic co-solvents on the activity of substrate specificity of feruloyl esterase. Bioresour. Technol. 2011, 102, 4962-4967. [CrossRef] [PubMed]

14. Antonopoulou, I.; Varriale, S.; Topakas, E.; Rova, U.; Christakopoulos, P.; Faraco, V. Enzymatic synthesis of bioactive compounds with high potential for cosmeceutical application. Appl. Microbiol. Biotechnol. 2016, 100, 6519-6543. [CrossRef] [PubMed]

15. Khmelnitsky, Y.L.; Hilhorst, R.; Verger, C. Detergentless microemulsions as media for enzymatic reactions. FEBS J. 1988, 176, 265-271. [CrossRef]

16. Topakas, E.; Vafiadi, C.; Christakopoulos, P. Microbial production, characterization and applications of feruloyl esterases. Process Biochem. 2007, 42, 497-509. [CrossRef]

17. Katsimpouras, C.; Antonopoulou, I.; Christakopoulos, P.; Topakas, E. Role and applications of feruloyl esterases in biomass bioconversion. In Microbial Enzymes in Bioconversion of Biomass, 1st ed.; Gupta, V., Ed.; Springer: Cham, Switzerland, 2016; pp. 79-123.

18. Dilokpimol, A.; Mäkelä, M.R.; Aguilar-Pontes, M.V.; Benoit-Gelber, I.; Hildén, K.S.; de Vries, R.P. Diversity of fungal feruloyl esterases: Updated phylogenetic classification, properties and industrial applications. Biotechnol. Biofuels 2016, 9, 231. [CrossRef] [PubMed]

19. Crepin, V.F.; Faulds, C.B.; Connerton, I.F. Functional classification of the microbial feruloyl esterases. Appl. Microbiol. Biotechnol. 2004, 63, 647-652. [CrossRef] [PubMed]

20. Benoit, I.; Danchin, E.G.J.; Blechrodt, R.-J.; de Vries, R.P. Biotechnological applications and potential of fungal feruloyl esterases based on prevalence, classification and biochemical diversity. Biotechnol. Lett. 2008, 30, 387-396. [CrossRef] [PubMed]

21. Dilokpimol, A.; Mäkelä, M.R.; Varriale, S.; Zhou, M.; Cerullo, G.; Gidijala, L.; Brás, J.L.A.; Jütten, P.; Piechot, A.; Verhaert, R.; et al. Fungal feruloyl esterases: Functional validation of genome mining based enzyme discovery including uncharacterized subfamilies. New Biotechnol. 2018, 41, 9-14. [CrossRef] [PubMed]

22. Vafiadi, C.; Topakas, E.; Nahmias, V.R.; Faulds, C.B.; Christakopoulos, P. Feruloyl esterase-catalysed synthesis of glycerol sinapate using ionic liquids mixtures. J. Biotechnol. 2009, 139, 124-129. [CrossRef] [PubMed] 
23. Vafiadi, C.; Topakas, E.; Bakx, E.J.; Schols, H.A.; Christakopoulos, P. Structural characterization of ESI-MS of feruloylated arabino-oligosaccharides synthesized by chemoenzymatic esterification. Molecules 2007, 12, 1367-1375. [CrossRef] [PubMed]

24. Vafiadi, C.; Topakas, E.; Christakopoulos, P. Regioselective esterase-catalyzed feruloylation of L-arabinobiose. Carbohydr. Res. 2006, 241, 1992-1997. [CrossRef] [PubMed]

25. Kelle, S.; Nieter, A.; Krings, U.; Zelena, K.; Linke, D.; Berger, R.G. Heterologous production of a feruloyl esterase from Pleurotus sapidus synthesizing feruloyl-saccharide esters. Biotechnol. Appl. Biochem. 2016, 63, 852-862. [CrossRef] [PubMed]

26. De Vries, R.P.; van Kuyk, P.A.; Kester, H.C.M.; Visser, J. The Aspergillus niger faeB gene induced in the presence of aromatic compounds. Biochem. J. 2002, 363, 377-386. [CrossRef] [PubMed]

27. Moukouli, M.; Topakas, E.; Christakopoulos, P. Cloning, characterization and functional expression of an alkalitolerant type C feruloyl esterase from Fusarium oxysporum. Appl. Microbiol. Biotechnol. 2008, 79, 245-254. [CrossRef] [PubMed]

28. Mäkelä, M.R.; Dilokpimol, A.; Koskela, S.; Kuuskeri, J.; de Vries, R.P.; Hilden, K. Characterization of a feruloyl esterase from Aspergillus terreus facilitates the division of fungal enzymes from Carbohydrate Esterase family 1 of the CAZy database. Microb. Biotechnol. 2018. [CrossRef] [PubMed]

29. Kühnel, S.; Pouvreau, L.; Appeldoorn, M.M.; Hinz, S.W.A.; Schols, H.A.; Gruppen, H. The ferulic acid esterases from Chrysosporium lucknowense C1: Purification, characterization and their potential application in biorefinery. Enzyme Microb. Technol. 2012, 50, 77-85. [CrossRef] [PubMed]

30. Dilokpimol, A.; Mäkelä, M.R.; Mansouri, S.; Belova, O.; Waterstraat, M.; Bunzel, M.; de Vries, R.P.; Hilden, K. Expanding the feruloyl esterase gene family of Aspergillus niger by characterization of feruloyl esterase, FaeC. New Biotechnol. 2017, 37, 200-209. [CrossRef] [PubMed]

31. Topakas, E.; Moukouli, M.; Dimarogona, M.; Christakopoulos, P. Expression, characterization and structural modelling of a feruloyl esterase from the thermophilic fungus Myceliophthora thermophila. Appl. Microbiol. Biotechnol. 2012, 94, 399-411. [CrossRef] [PubMed]

32. De Vries, R.P.; Michelsen, B.; Roulsen, C.H.; Kroon, P.A.; van den Heuvel, R.H.; Faulds, C.B.; Williamson, G.; van den Hombergh, J.P.; Visser, J. The faeA genes from Aspergillus niger and Aspergillus tubingensis encode ferulic acid esterases involved in degradation of complex cell wall polysaccharides. Appl. Environ. Microbiol. 1997, 63, 4638-4644. [PubMed]

33. Suzuki, K.; Hori, A.; Kawamoto, K.; Thangudu, R.R.; Ishida, T.; Igarashi, K.; Samejima, M.; Yamada, C.; Arakawa, T.; Wakagi, T.; et al. Crystal structure of a feruloyl esterase belonging to the tannase family: A disulfide bond near a catalytic triad. Proteins 2014, 82, 2857-2867. [CrossRef] [PubMed]

34. Komiya, D.; Hori, A.; Ishida, T.; Igarashi, K.; Samejima, M.; Koseki, T.; Fushinobu, S. Crystal structure and substrate specificity modification of acetyl xylan esterase from Aspergillus luchuensis. Appl. Environ. Microbiol. 2017, 83, e01251-17. [CrossRef] [PubMed]

35. Visser, H.; Joosten, V.; Punt, P.J.; Gusakov, A.V.; Olson, P.T.; Joosten, R.; Bartels, J.; Visser, J.; Sinitsyn, A.P.; Emalfarb, M.A.; et al. Development of a mature fungal technology and production platform for industrial enzymes based on a Myceliophthora thermophila isolate, previously known as Chrysosporium lucknowense C1. Ind. Biotechnol. 2011, 7, 214-223. [CrossRef]

36. Verdoes, J.C.; Punt, P.J.; Burlingame, R.P.; Pynnonen, C.M.; Olson, P.T.; Wery, J. New Fungal Production System. Patent No. WO2010107303 A2, 23 September 2010.

37. Petersen, T.N.; Brunak, S.; von Hejine, G.; Nielsen, H. SignalP 4.0: Discriminating signal peptides from transmembrane regions. Nat. Methods 2011, 8, 785-786. [CrossRef] [PubMed]

38. Gasteiger, E.; Hoogland, C.; Gattiker, A.; Duvaud, S.; Wilkins, M.R.; Appel, R.D.; Bairoch, A. Protein identification and analysis tools on the ExPASy Server. In The Proteomics Protocols Handbook, 1st ed.; Walker, J.M., Ed.; Humana Press: New York, NY, USA, 2005; pp. 571-607.

39. Steentoft, C.; Vakhrushev, S.Y.; Joshi, H.J.; Kong, Y.; Vester-Christensen, M.B.; Schjoldager, K.T.-B.G.; Lavrsen, K.; Dabelsteen, S.; Pedersen, N.B.; Marcos-Silva, L.; et al. Precision mapping of the human O-GalNAc glycoproteome through SimpleCell technology. EMBO J. 2013, 32, 1478-1488. [CrossRef] [PubMed]

40. Krieger, E.; Joo, K.; Lee, J.; Lee, J.; Raman, S.; Thompson, J.; Tyka, M.; Baker, D.; Karplus, K. Improving physical realism, stereochemistry, and side-chain accuracy in homology modeling: Four approaches that performed well in CASP8. Proteins 2009, 77, 114-122. [CrossRef] [PubMed] 
41. Trott, O.; Olson, A.J. AutoDock Vina: Improving the speed and accuracy of docking with a new scoring function, efficient optimization and multithreading. J. Comput. Chem. 2010, 31, 455-461. [CrossRef] [PubMed]

42. Hermoso, J.A.; Aparicia, J.S.; Molina, R.; Juge, N.; Gonzalez, R.; Faulds, C.B. The crystal structure of feruloyl esterase A from Aspergillus niger suggests evolutive functional convergence in feruloyl esterase family. J. Mol. Biol. 2004, 338, 495-506. [CrossRef] [PubMed]

43. Krieger, E.; Vriend, G. YASARA View-Molecular graphic for all devices- from smartphones to workstations. Bioinformatics 2014, 9, 114-122. [CrossRef] [PubMed]

(C) 2018 by the authors. Licensee MDPI, Basel, Switzerland. This article is an open access article distributed under the terms and conditions of the Creative Commons Attribution (CC BY) license (http:/ / creativecommons.org/licenses/by/4.0/). 